\title{
Evaluation of Turbulent Surface Flux Parameterizations for the Stable Surface Layer over Halley, Antarctica*
}

\author{
John J. CASSAno ${ }^{+}$and Thomas R. Parish \\ Department of Atmospheric Science, University of Wyoming, Laramie, Wyoming \\ JOHN C. KING \\ British Antarctic Survey, Cambridge, United Kingdom
}

(Manuscript received 12 April 1999, in final form 28 April 2000)

\begin{abstract}
Calculated surface fluxes from seven surface layer parameterizations are verified against 45 months of observations from Halley, Antarctica, with a temporal resolution of $1 \mathrm{~h}$. The surface layer parameterizations are taken from widely used numerical models including the National Center for Atmospheric Research (NCAR) Community Climate models CCM2 and CCM3, the U.K. Met. Office Unified Climate Model, and the fifthgeneration Pennsylvania State University-NCAR Mesoscale Model (MM5). The observations include measurements of the mean wind speed and temperature inversion strength and direct measurements of the turbulent fluxes of heat and momentum.

A comparison of the calculated and observed fluxes is conducted for conditions in which the surface layer is stably stratified. Based on these comparisons it is found that the simulated friction velocity values are adequate (although slightly larger than the observed turbulent fluxes) under all but the highest bulk Richardson number conditions (greatest static stability). In contrast the magnitude of the calculated sensible heat flux is frequently less than that of the observed sensible heat flux. The use of a larger scalar roughness length for heat compared to that for momentum is found to remove this bias in the calculated sensible heat fluxes.

The correlation between the observed and calculated fluxes of heat and momentum is acceptable for the lower bulk Richardson number regimes, but is near zero for the high bulk Richardson number regime. The correlation between the calculated and observed fluxes is in general better for the momentum flux than for the sensible heat flux.

The bias in the calculated sensible heat flux could have significant implications for numerical simulations in which the flow is driven by surface processes, and may pose problems for climate-scale simulations. The impact that errors of the observed magnitude have on simulated katabatic winds is explored with a series of twodimensional numerical simulations using MM5. Inferences about the relevance of these findings for climate simulations are also addressed.
\end{abstract}

\section{Introduction}

The effects of turbulent transfer between the atmosphere and the surface are included in numerical weather prediction models with surface layer (SL) parameterizations. These parameterizations relate mean atmospheric and surface properties that are forecast by the numerical model, to turbulent fluxes of heat, momen-

\footnotetext{
* Byrd Polar Research Center Contribution Number 1192.

+ Current affiliation: Polar Meteorology Group, Byrd Polar Research Center, The Ohio State University, Columbus, Ohio.
}

Corresponding author address: Dr. John J. Cassano, Polar Meteorology Group, Byrd Polar Research Center, The Ohio State University, 1090 Carmack Road, Columbus, OH 43210.

E-mail: cassano@polarmet1.mps.ohio-state.edu tum, and other scalar quantities. In this way the atmosphere and the underlying surface in the model are coupled.

For many atmospheric flows the coupling of the atmosphere and the surface is critical. One example of a flow regime where the accurate simulation of surface turbulent fluxes is a necessity is the continent-wide katabatic flows of the Antarctic, which are driven by cooling of the atmosphere closest to the surface. This cooling is in large part accomplished by the turbulent transfer of heat from the atmosphere to the underlying, radiatively cooled ice surface. Some situations in which accurate forecasts of the turbulent transfer of momentum from the atmosphere to the surface are important include the forcing of wave and sea ice models.

Considering a larger portion of the atmosphere, the heat transfer between the atmosphere and surface can be a large component of the diabatic temperature ten- 
dency of the atmospheric column, especially in the absence of moist processes. Errors in the parameterization of this turbulent heat transfer in climate simulations could lead to errors in the forecast baroclinicity of the atmosphere and, thus, the resulting atmospheric circulation patterns (Stull 1988, 21-22).

King and Connolley (1997) and Hines et al. (1999) have presented the verification of SL parameterizations in the Antarctic. King and Connolley compared measurements of the surface energy budget at four locations in the Antarctic with the forecast surface energy budget from the U.K. Met. Office (UKMO) Unified Climate Model. Measurements of the net radiation budget and calculation of the heat flux through the snowpack allowed them to determine the turbulent heat flux as a residual of the surface energy budget. For three of the four sites considered the modeled turbulent heat flux from the atmosphere to the surface exceeded the observed turbulent heat flux, and at the fourth site the modeled and observed quantities were nearly equal. They attributed the error in the calculated turbulent heat flux to errors in the stability correction function used in the SL parameterization.

Hines et al. (1999) performed a similar analysis using the National Centers for Environmental Prediction (NCEP) global spectral model medium-range forecasts (MRF). In this study they compared the predicted surface turbulent sensible heat $(\mathrm{SH})$ flux from the model during three special observing periods of the Antarctic First Regional Observing Study of the Troposphere (July 1994, 15 Oct-15 Nov 1994, and Jan 1995) to the multiyear (1986-88) average surface turbulent SH fluxes given by King and Connolley (1997) for the South Pole. As in the King and Connolley study, Hines et al. found that the SL parameterizations in the MRF model overestimated the downward-directed SH flux from the atmosphere to the surface compared to the observed values. They hypothesized that this bias could be related to the stability correction function used in the SL parameterization.

The interpretation of the results from these studies is somewhat ambiguous because the calculated fluxes are dependent on the model forecast values of wind speed and low-level temperature inversion strength, the model vertical resolution, and any errors in the SL parameterizations. Biases in the model forecast quantities could lead to biases in the calculated turbulent fluxes, which are not a function of the SL parameterization being employed.

In the current paper results from a comparison of the surface turbulent fluxes calculated with seven SL parameterizations to fluxes observed at the British Antarctic Survey (BAS) base at Halley, Antarctica, are presented. The SL parameterizations that are used in this study are taken from mesoscale to climate-scale numerical models, to obtain results that are applicable to a wide range of model users. The observational dataset includes measurements of the mean wind speed and low- level temperature inversion strength as well as direct measurements of the turbulent $\mathrm{SH}$ and momentum fluxes. The turbulent fluxes are calculated with the SL parameterizations using the observed mean quantities and are compared to the observed turbulent fluxes (i.e., the SL parameterizations are used in an "offline" mode). In this way the ambiguity introduced into the evaluation of the SL parameterizations encountered by King and Connolley (1997) and Hines et al. (1999) is avoided. This approach requires additional simulations using the SL parameterization coupled to a numerical model to determine how the SL parameterization, and any errors in the parameterization, interact with the model.

The effects that errors in the SL parameterizations could have on numerical simulations of the Antarctic katabatic circulation are also considered in a series of two-dimensional (2D), idealized numerical simulations of the Antarctic katabatic wind regime. The results of these simulations are analyzed in terms of both the local differences in the katabatic flow and the larger-scale impacts that are caused by the errors in the SL parameterizations.

In the next section a discussion of the dataset used for this study is presented, followed in section 3 by a comparison of the observed and calculated turbulent fluxes. Section 4 describes the numerical model used for the sensitivity studies and the results of these simulations. The paper concludes with a summary of the findings and a discussion of future research goals.

\section{Surface layer measurements at Halley}

\section{a. Measurement site and instrumentation}

Direct measurements of turbulent fluxes in the Antarctic are quite limited (Adachi 1974; Kobayashi and Ishida 1979; King et al. 1989; King and Anderson 1994). The BAS has conducted a number of experiments that have measured mean and turbulent quantities in the SL. The data used in this paper were collected at Halley during the period February 1995 through October 1998. The BAS base at Halley $\left(75^{\circ} \mathrm{S}, 26^{\circ} \mathrm{W}\right)$ is located on the flat Brunt Ice Shelf, which has a nearly uniform, smooth surface. The flat ice shelf gives way to the steep slopes of the Antarctic continent approximately $30 \mathrm{~km}$ to the southeast of Halley. East of the measurement site the ice shelf extends for over $40 \mathrm{~km}$ providing a long, uninterrupted fetch for the prevailing easterly winds (King 1990; King and Anderson 1994).

The instruments used to measure the characteristics of the SL were mounted on an 8-m tower approximately $400 \mathrm{~m}$ southeast of the main base buildings. This location was upwind of the station for the dominant wind direction, and thus the measurements under the mean conditions were not affected by the structures on the base. The instruments of interest for the current project include an ultrasonic anemometer-thermometer (Kaijo Denki Model DAT-100) that was mounted at a height 
that varied from 3.5 to $4.9 \mathrm{~m}$ during the period February 1995-October 1998, as a result of snow accumulation and manual repositioning of the instrument. This instrument provided measurements of the wind and temperature fluctuations and was mounted on a boom that extended $1.2 \mathrm{~m}$ beyond the mast, and pointed due east. This orientation was chosen to minimize transducer shadowing errors (Wyngaard and Zhang 1985; Grant and Watkins 1989). The mean air temperature was measured with a platinum resistance thermometer in a radiation shield, with forced ventilation, that was mounted at the same height as the ultrasonic anemometer-thermometer. The surface temperature was measured with a platinum resistance thermometer that was kept in contact with the snow surface by manually repositioning the instrument on a daily basis.

\section{b. Data processing}

All the instruments produced analog outputs that were sampled by an analog-to-digital converter. The ultrasonic anemometer-thermometer was oversampled at 40 $\mathrm{Hz}$ and block averaged to $20 \mathrm{~Hz}$ to minimize aliasing. The mean surface and air temperature measurements were sampled at $1 \mathrm{~Hz}$. All the data were then averaged to produce $10-\mathrm{min}$ mean values of wind speed, wind direction, air temperature, and surface temperature. Data from the ultrasonic anemometer were rotated to an along-flow coordinate system, and mean turbulent fluxes of heat and momentum were computed from the ultrasonic anemometer-thermometer measurements using an eddy correlation technique for each $10-$ min period. The 10 -min mean values were further averaged to produce 1 -h mean values of all quantities. This additional averaging reduced the size of the dataset and reduced the scatter of the turbulence measurements. It should be noted that using the 10-min average values to produce the 1-h average values is not equivalent to averaging the raw data over a 1 -h period. By using the $10-$ min mean values to produce the $1-\mathrm{h}$ mean values, low-frequency (periods $\geq 10 \mathrm{~min}$ ) contributions to the turbulent fluxes were excluded. (Contributions to the turbulent fluxes by gravity waves with periods $\geq 10$ min were not removed from the averaged fluxes since the gravity wave contribution could not be evaluated without the covariance spectra, which were not archived due to limited storage capacity.)

Error analysis of the ultrasonic anemometer-thermometer measurements has been discussed by King (1990) and King and Anderson (1994). The problem of most concern was transducer shadowing (Wyngaard and Zhang 1985; Grant and Watkins 1989), and this problem was minimized by including only observations with a wind direction within $\pm 30^{\circ}$ of the instrument axis (wind directions between $60^{\circ}$ and $120^{\circ}$ ). This instrument was also carefully leveled and subsequent analysis of the data failed to indicate spurious mean vertical velocities that could be attributed to instrument tilt (King and An- derson 1994). The ultrasonic anemometer-thermometer was heated to avoid problems caused by frost or rime accumulation on the sensor. (The heaters were used continuously and did not cause differences in the measured $\mathrm{SH}$ fluxes when compared to an unheated ultrasonic anemometer-thermometer.) In addition, observations in which errors in the ultrasonic measurements caused by blowing snow were excluded from the dataset by applying simple objective tests on the measured variances of the horizontal wind components (King and Anderson 1994). Also, all periods when the mean wind speed exceeded $11 \mathrm{~m} \mathrm{~s}^{-1}$ were excluded from the dataset, since this wind speed was found to be the typical threshold for the onset of dense blowing snow at the height of the ultrasonic anemometer-thermometer (King 1990).

The measurement of the surface temperature was also prone to error, with errors due to solar radiation effects during the summer and misrepresentation of the surface temperature when the probe temporarily became buried by snow. Repositioning the probe on a daily basis minimized the second error. Also, cases in which strong winds $\left(>11 \mathrm{~m} \mathrm{~s}^{-1}\right)$ that could lead to deposition or scouring of snow in the vicinity of the surface temperature probe were excluded from the dataset. Solar radiation errors were avoided by only considering cases when the sun was below the local horizon.

Data from the period February 1995-October 1998 were edited to remove cases with wind direction outside of the allowed range (as discussed above), wind speeds in excess of $11 \mathrm{~m} \mathrm{~s}^{-1}$, and solar elevation angles greater than $0^{\circ}$. The dataset was further reduced by considering only those cases in which the potential temperature was observed to increase from the surface to the height of the instrument boom. Therefore only cases in which the near-surface air was stably stratified were considered. A total of 3963 hourly observations satisfied these criteria during the observation period.

\section{Verification of the surface layer parameterizations}

\section{a. Description of the surface layer parameterizations}

Seven SL parameterizations are evaluated using the turbulent surface flux measurements from Halley. These parameterizations are selected due to their use in a number of mesoscale to climate-scale numerical models, although the selected SL parameterizations represent a small number of those available to numerical modelers. Specifically the SL parameterizations considered include the SL parameterizations from the National Center for Atmospheric Research (NCAR) Community Climate Models versions two (CCM2 SL) (Hack et al. 1993) and three (CCM3 SL) (Kiehl et al. 1996), the SL parameterization from the U.K. Met. Office Unified Climate Model (UKMO SL) (King and Connolley 1997), two SL parameterizations available in the Pennsylvania State University (PSU)-NCAR fifth-generation Mesoscale 
TABLE 1. Diagnostic equations for the SH flux and $u_{*}$ used in the seven SL parameterizations considered in this paper. Variables used in this table are described in the text.

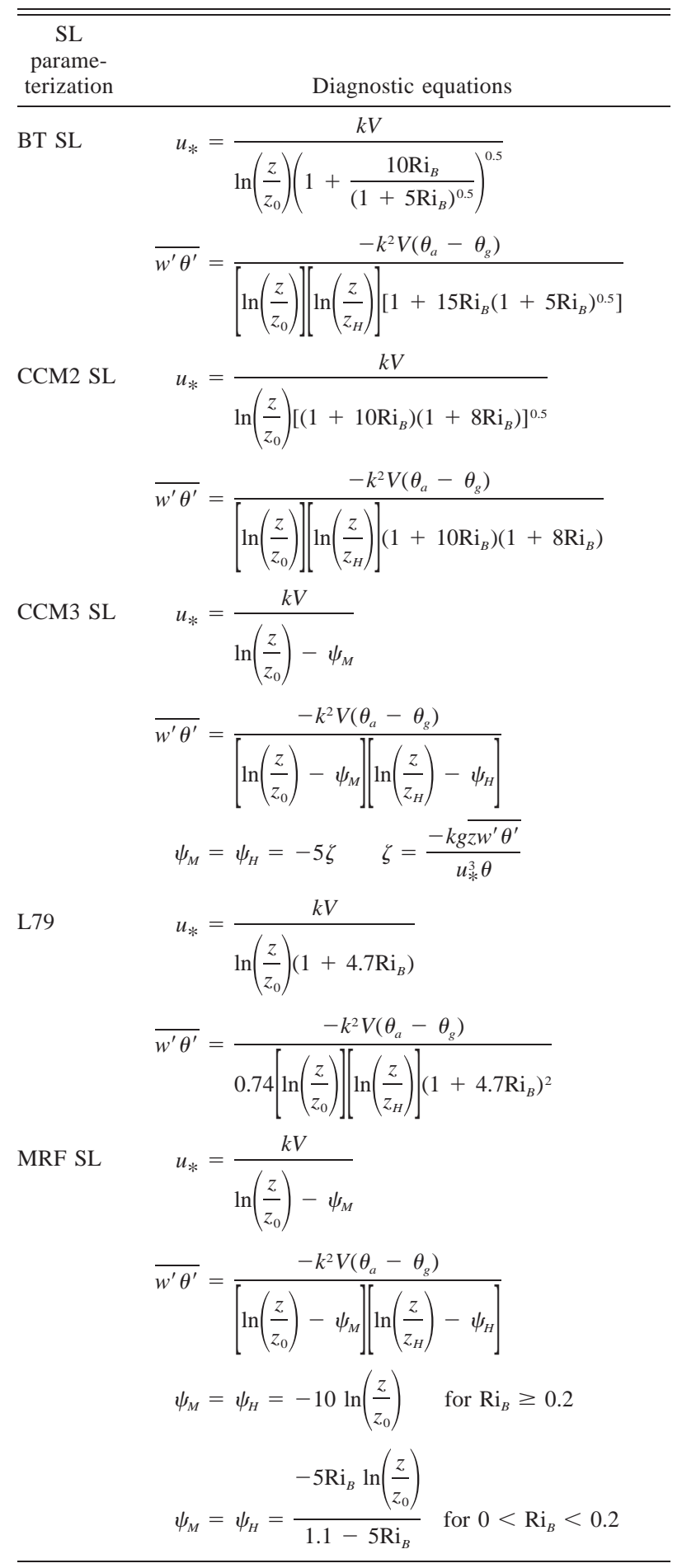

Model (MM5), the SL parameterization from the Parish and Waight (1987) mesoscale model (PW87 SL) (which has been used extensively in the simulation of Antarctic katabatic flows), and an SL parameterization described
TABLE 1. (Continued)

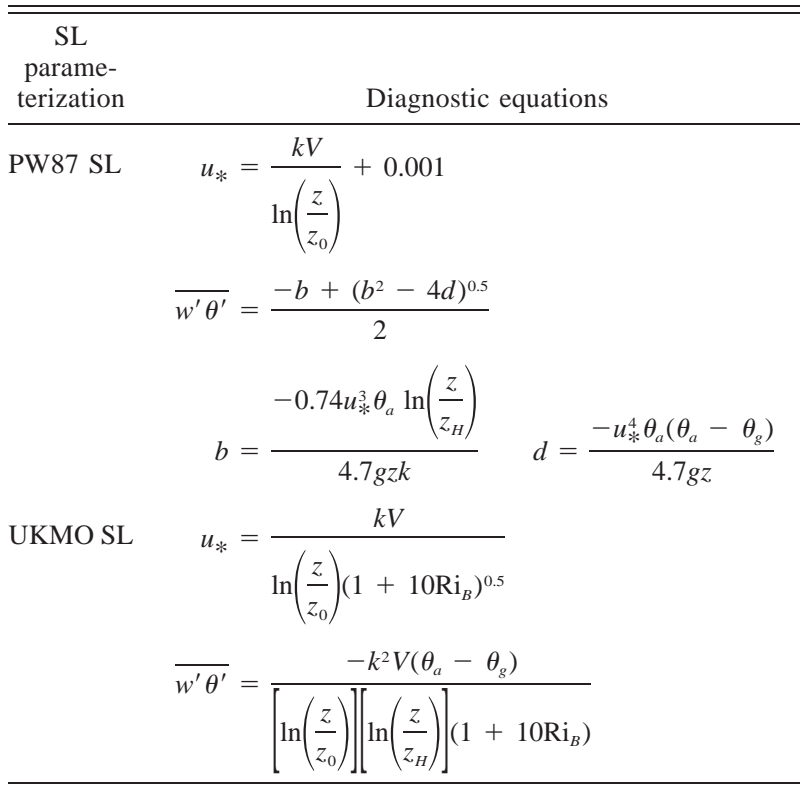

by Louis (1979) (L79 SL). One of the parameterizations from the MM5 is incorporated into the Burk and Thompson (1989) turbulence parameterization routine in that model and is referred to as the BT SL. The second parameterization from the MM5 is used in both the MRF (Hong and Pan 1996) and the high-resolution Blackadar (Blackadar 1976; Zhang and Anthes 1982) turbulence parameterizations in MM5, and is referred to as the MRF SL.

Table 1 lists the diagnostic equations for the kinematic SH flux, $\overline{w^{\prime} \theta^{\prime}}$, and the friction velocity, $u_{*}$, for the seven SL parameterizations used in this study. All calculations of the turbulent fluxes (and bulk Richardson number) with the parameterizations use identical requirements for minimum values of the wind speed $\left(V \geq 1 \mathrm{~m} \mathrm{~s}^{-1}\right)$ and the friction velocity $\left(u_{*} \geq 0.1 \mathrm{~m} \mathrm{~s}^{-1}\right)$. This was done to maintain consistency with the methods used to implement the SL parameterizations in many numerical models. Other minimum values used for the calculations include $\psi_{M}$ and $\psi_{H} \geq-5$ for the CCM3 SL and $\psi_{M}$ and $\psi_{H} \geq-10$ for the MRF SL, where $\psi_{M}$ and $\psi_{H}$ are the stability correction functions in these parameterizations.

Some of the variables used in Table 1, and not defined therein, include the potential temperature at the height of the instrument boom, $\theta_{a}$; the potential temperature of the surface, $\theta_{g}$; the von Kármán constant, $k$; the height of the instrument boom above the surface, $z$; the surface roughness length for momentum, $z_{0}$; the scalar roughness length for heat, $z_{H}$; and the acceleration due to gravity, $g$. Values assigned to the constants $k$ and $g$ are 0.4 and $9.81 \mathrm{~m} \mathrm{~s}^{-2}$, respectively. The value of $z_{0}$ is taken as $1.1 \times 10^{-4} \mathrm{~m}$ following the results in King (1990). Initial evaluation of the SL parameterizations assumes that $z_{H}=z_{0}$, as is commonly assumed in many numerical models. The implications of this assumption are 
discussed in section $3 \mathrm{c}$. The values used for $\theta_{a}$ and $\theta_{g}$ are calculated from the air and surface temperature (measured with platinum resistance thermometers) and from $z$. The value of $V$ used for all calculations is based on the measured 1-h mean wind speed from the ultrasonic anemometer, subject to the minimum value requirement listed in the previous paragraph. The bulk Richardson number, $\mathrm{Ri}_{B}$, is calculated as

$$
\mathrm{Ri}_{B}=\frac{g z\left(\theta_{a}-\theta_{g}\right)}{\left(\frac{\theta_{a}+\theta_{g}}{2}\right) V^{2}} .
$$

The basic equations for $u_{*}$ and the $\mathrm{SH}$ flux for all the parameterizations (except for the equation for the SH flux in the PW87 SL) are derived by integrating the neutral limit dimensionless wind shear, $\phi_{m}$, and temperature gradient, $\phi_{h}$, equations of Businger et al. (1971) from a height of $z_{0}$ to $z$, and including an empirically determined stability correction function. The stability correction function varies among the seven SL parameterizations considered, and is taken to be a function of $\mathrm{Ri}_{B}$ or $\zeta$ (both of which represent the SL stability) as shown in Table 1 . The PW87 SL neglects the stability correction term for $u_{*}$ and therefore diagnoses larger values of $u_{*}$ than the other SL parameterizations as the static stability increases. Another difference between the PW87 SL parameterization and the other SL parameterizations is that the SH flux in the PW87 SL is calculated by integrating the Businger et al. (1971) expression for $\phi_{h}$ under statically stable conditions from height $z_{H}$ to $z$ and solving the resulting quadratic equation. The stability correction function is incorporated into this solution, since the expression for $\phi_{h}$ already includes the effects of the stable stratification.

Considering the discussion above, it is seen that all the SL parameterizations evaluated in this paper are based on Monin-Obukhov similarity theory. Results presented by King and Anderson (1994) suggest that Monin-Obukhov similarity theory provides an adequate description of the SL observed at Halley under statically stable conditions, although the roughness length for heat may be much larger than that used for momentum. These findings are discussed further in the context of the SL parameterization verification results presented below. Observed near-surface profiles of wind and temperature discussed by King (1990) indicate that above a height of approximately $5 \mathrm{~m}$ the Monin-Obukhov similarity functions do not provide a good description of the observed profiles. (The implications of this finding are explored in section 4 using a series of numerical model sensitivity experiments in which the depth of the SL, determined by the height of the lowest model level, is varied.)

\section{b. Comparison of parameterized and observed surface turbulent fluxes}

The wind speeds and low-level temperature inversion strengths observed during the 45-month period of the

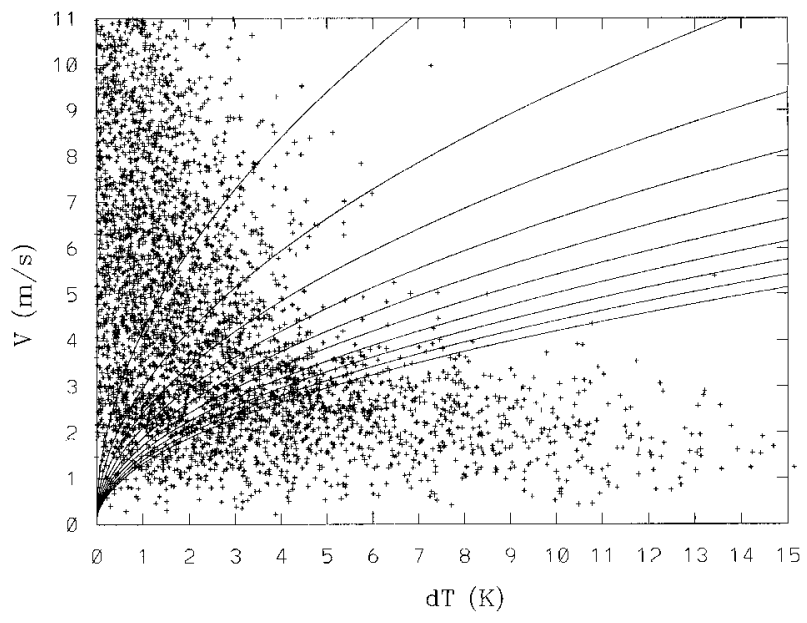

FIG. 1. Scatterplot of the observed wind speed, $V$, and the lowlevel temperature inversion strength, $d T$, at Halley from Feb 1995 to Oct 1998. Contours of the bulk Richardson number [contour interval of 0.01 with contours from 0.01 (uppermost contour) to 0.1 (lowermost contour)] are superimposed in the figure and are calculated assuming a measurement height of $4.5 \mathrm{~m}$.

dataset are displayed in Fig. 1, as a scatterplot, with each point representing a single 1-h averaged observation. The low-level temperature inversion strength, $d T$, in Fig. 1 is calculated by subtracting the surface potential temperature from the mean potential temperature of the air. Superimposed on the scatterplot are contours of $\mathrm{Ri}_{B}$ that are calculated by assuming an observation height for $V$ and $\theta_{a}$ of $4.5 \mathrm{~m}$.

Three stability regimes can be identified from Fig. 1, based on a rough clustering of the data. The first corresponds to low values of $\mathrm{Ri}_{B}(<0.02)$, in which the low-level temperature inversion is weak and/or the wind speed is large. A second regime can be identified in which $\mathrm{Ri}_{B}$ is large $(>0.1)$, corresponding to a strong low-level temperature inversion and weak wind conditions $\left(V<3 \mathrm{~m} \mathrm{~s}^{-1}\right)$. Finally, an intermediate regime, with intermediate values of $\mathrm{Ri}_{B}$, wind speed, and lowlevel temperature inversion strength, is identified. Verification of the SL parameterizations takes advantage of this rough grouping of the data to determine if any consistent errors in the parameterizations are due to specific stability classes.

The equations presented in Table 1 are used to calculate the surface SH flux and $u_{*}$ for each 1 -h averaged observation in the dataset (thus the turbulent flux calculations are performed in an offline mode). The normalized difference between the calculated and observed fluxes, defined as

$$
\mathrm{ND}=\frac{\text { flux }_{\mathrm{calc}}-\text { flux }_{\mathrm{obs}}}{\text { flux }_{\mathrm{obs}}},
$$

is used as a measure of the error between the calculated and observed fluxes. The frequency distribution of ND is determined for each SL parameterization and is shown for $u_{*}\left(\mathrm{ND}_{u *}\right)$ in Fig. 2 and for the $\mathrm{SH}$ flux $\left(\mathrm{ND}_{\mathrm{SH}}\right)$ in 

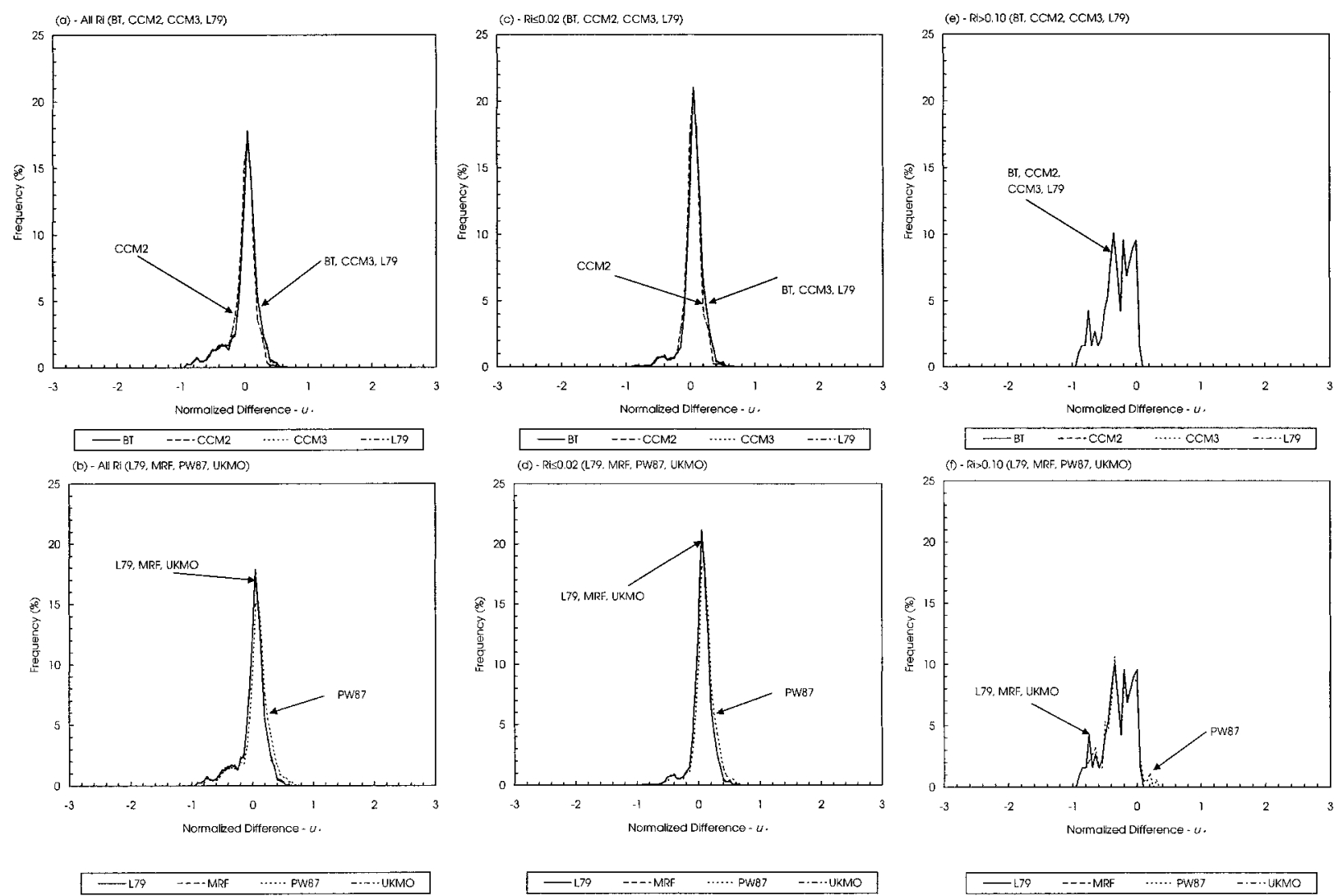

FIG. 2. (a), (b) Frequency distribution of $\mathrm{ND}_{u *}$ for all observations; (c), (d) observations with $\mathrm{Ri}_{B} \leq 0.02$; and (e), (f) observations with $\mathrm{Ri}_{B}>0.1$. (a), (c), (e) Results from the BT, CCM2, CCM3, and L79 SL parameterizations; and (b), (d), and (f) results from the L79, MRF, PW87, and UKMO SL parameterizations.

Fig. 3. Additional statistics from this analysis are presented in Tables 2 and 3, for $u_{*}$ and the SH flux, respectively. In addition, a linear regression curve calculated with the method of least squares, for flux $x_{\text {calc }}$ as a function of flux ${ }_{\text {obs }}$, is determined. The slope and intercept of this line, as well as the correlation coefficient and index of agreement (Willmott 1982), are calculated and these results are also included in Tables 2 and 3. All results in the figures and tables discussed above use turbulent fluxes calculated with the SL parameterizations in which $z_{H}$ is assumed to be equal to $z_{0}(=1.1 \times$ $\left.10^{-4} \mathrm{~m}\right)$.

\section{1) Comparison of OBSERVED AND CALCUlATED $u_{*}$ VALUES}

Figure 2 displays the frequency distribution of $\mathrm{ND}_{u *}$ for all observed $\mathrm{Ri}_{B}$ values (Figs. $2 \mathrm{a}$ and $2 \mathrm{~b}$ ), for $\mathrm{Ri}_{B}$ $\leq 0.02$ (Figs. $2 \mathrm{c}$ and $2 \mathrm{~d}$ ), and for $\mathrm{Ri}_{B}>0.10$ (Figs. $2 \mathrm{e}$ and $2 \mathrm{f}$ ). Only cases in which the observed $u_{*} \geq 0.1 \mathrm{~m}$ $\mathrm{s}^{-1}$ are considered when evaluating the SL parameterizations, since values of $u_{*}$ smaller than this are not calculated with the SL parameterizations due to the lower limit imposed on $u_{*}$ in the parameterizations. This reduces the number of hourly observations considered from 3963 to 2427.

From the results in Fig. 2 and Table 2 it is apparent that the calculated values of $u_{*}$ are nearly identical for all seven SL parameterizations considered. The PW87 SL parameterization tends to calculate slightly larger values of $u_{*}$ than the other SL parameterizations, as expected given the neglected stability correction function in this parameterization.

Evaluation of the calculated $u_{*}$ values for the entire dataset $\left(\right.$ all $\left.\mathrm{Ri}_{B}\right)$ and the weak static stability cases $\left(\mathrm{Ri}_{B}\right.$ $\leq 0.02$ ) indicates that the calculated values of $u_{*}$ are slightly larger than the observed values, with median $\mathrm{ND}_{u} *$ values ranging from 0.00 to 0.07 (Table 2, Figs. $2 \mathrm{a}-\mathrm{d}$ ), with more than half of the cases having $\mathrm{ND}_{u *}$ $>0$ (except for the CCM2 SL for the entire dataset). The distribution of $\mathrm{ND}_{u *}$ is narrow, with more than $70 \%$ of the cases having $-0.2<\mathrm{ND}_{u *} \leq 0.2$. This indicates that the calculated values of $u_{*}$ are generally close to the observed values. The linear regression analysis for these two static stability classes further reveals the generally good agreement between the calculated and observed $u_{*}$ values (correlation coefficient $>0.60$ for the entire dataset and $=0.77$ for the weak static stability 

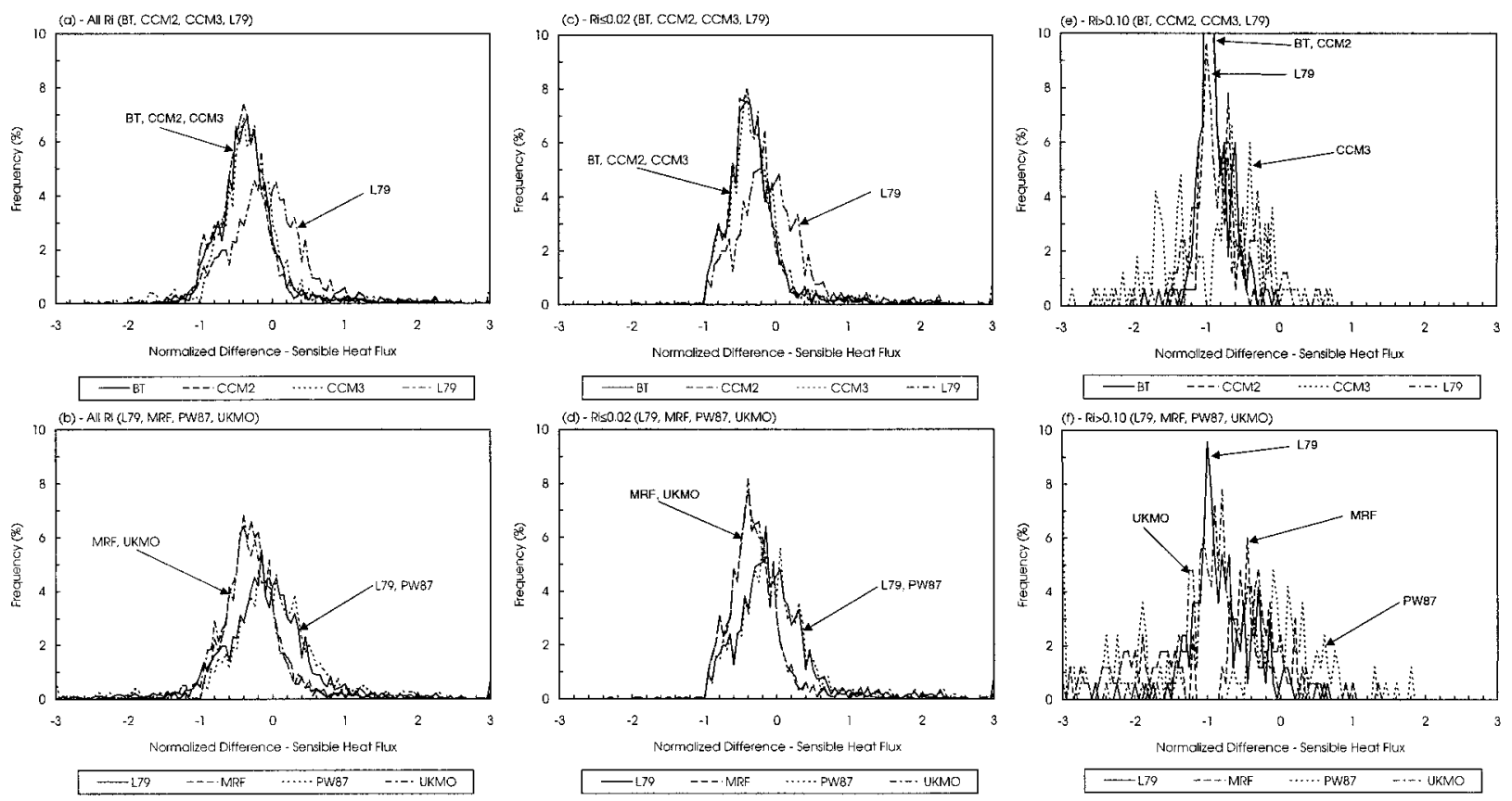

FIG. 3. Same as Fig. 2 except for $\mathrm{ND}_{\mathrm{SH}}$.

TABLE 2. Statistics from the comparison of the observed and calculated values of $u_{*}$. Here, SL refers to the surface layer parameterization used to calculate the turbulent fluxes; $\mathrm{Ri}_{B}$ denotes the range of bulk Richardson numbers considered when calculating the statistics; ND refers to the normalized difference between the calculated and observed fluxes, as described in the text; IOA is the index of agreement; correl. is the correlation coefficient between the calculated and observed fluxes; and int. and slope are the parameters for the best-fit linear regression line.

\begin{tabular}{|c|c|c|c|c|c|c|c|c|c|}
\hline \multirow[b]{3}{*}{ SL } & \multirow[b]{3}{*}{$\mathrm{Ri}_{B} *$} & \multirow{3}{*}{$\begin{array}{c}\text { Median } \\
\text { ND }\end{array}$} & \multirow{2}{*}{\multicolumn{3}{|c|}{$\%$ of obs with }} & \multirow[b]{3}{*}{ IOA } & \multicolumn{3}{|c|}{ Linear regression } \\
\hline & & & & & & & & Int. & \\
\hline & & & $-1<\mathrm{ND} \leq 0$ & $0<\mathrm{ND} \leq 1$ & $-0.2<\mathrm{ND} \leq 0.2$ & & Correl. & $\left(\mathrm{m} \mathrm{s}^{-1}\right)$ & Slope \\
\hline BT & All & 0.02 & 42.7 & 57.3 & 75.6 & 0.76 & 0.61 & 0.11 & 0.46 \\
\hline CCM2 & All & 0.00 & 51.1 & 48.9 & 78.2 & 0.77 & 0.61 & 0.10 & 0.47 \\
\hline CCM3 & All & 0.01 & 44.7 & 55.3 & 76.3 & 0.76 & 0.61 & 0.11 & 0.46 \\
\hline L79 & All & 0.02 & 42.9 & 57.1 & 75.8 & 0.76 & 0.61 & 0.11 & 0.46 \\
\hline MRF & All & 0.02 & 43.3 & 56.7 & 75.8 & 0.76 & 0.61 & 0.11 & 0.46 \\
\hline PW87 & All & 0.05 & 33.8 & 66.2 & 69.6 & 0.76 & 0.60 & 0.12 & 0.45 \\
\hline UKMO & All & 0.02 & 43.0 & 57.0 & 75.9 & 0.76 & 061 & 0.11 & 0.46 \\
\hline BT & $\leq 0.02$ & 0.04 & 33.1 & 66.9 & 84.3 & 0.86 & 0.77 & 0.10 & 0.59 \\
\hline CCM2 & $\leq 0.02$ & 0.02 & 40.7 & 59.3 & 87.4 & 0.86 & 0.77 & 0.09 & 0.60 \\
\hline CCM3 & $\leq 0.02$ & 0.04 & 33.9 & 66.1 & 84.9 & 0.86 & 0.77 & 0.10 & 0.59 \\
\hline L79 & $\leq 0.02$ & 0.04 & 32.9 & 67.1 & 84.3 & 0.86 & 0.77 & 0.10 & 0.59 \\
\hline MRF & $\leq 0.02$ & 0.04 & 32.9 & 67.1 & 84.6 & 0.86 & 0.77 & 0.10 & 0.59 \\
\hline PW87 & $\leq 0.02$ & 0.07 & 25.4 & 74.6 & 78.3 & 0.86 & 0.77 & 0.11 & 0.58 \\
\hline UKMO & $\leq 0.02$ & 0.04 & 33.2 & 66.8 & 84.5 & 0.86 & 0.77 & 0.10 & 0.59 \\
\hline BT & $>0.10$ & -0.31 & 98.4 & 1.6 & 34.9 & 0.32 & 0.04 & 0.10 & 0.00 \\
\hline CCM2 & $>0.10$ & -0.31 & 98.4 & 1.6 & 34.9 & 0.33 & 0.00 & 0.10 & 0.00 \\
\hline CCM3 & $>0.10$ & -0.31 & 98.4 & 1.6 & 34.9 & 0.33 & 0.04 & 0.10 & 0.00 \\
\hline L79 & $>0.10$ & -0.31 & 98.4 & 1.6 & 34.9 & 0.33 & 0.00 & 0.10 & 0.00 \\
\hline MRF & $>0.10$ & -0.31 & 98.4 & 1.6 & 34.9 & 0.33 & 0.00 & 0.10 & 0.00 \\
\hline PW87 & $>0.10$ & -0.30 & 95.2 & 4.8 & 37.0 & 0.31 & 0.21 & 0.04 & 0.00 \\
\hline UKMO & $>0.10$ & -0.31 & 98.4 & 1.6 & 34.9 & 0.32 & 0.04 & 0.10 & 0.00 \\
\hline
\end{tabular}

* Calculated statistics for cases with observed $u_{*} \geq 0.1 \mathrm{~m} \mathrm{~s}^{-1} ; n=2427$ for all $\mathrm{Ri}_{B,} n=1852$ for $\mathrm{Ri}_{B} \leq 0.02$, and $n=189$ for $\mathrm{Ri}_{B}>$ 0.10 . 
TABLE 3. Same as Table 2 except the statistics are from the comparison of the observed and calculated values of the SH flux.

\begin{tabular}{|c|c|c|c|c|c|c|c|c|c|}
\hline \multirow[b]{2}{*}{ SL } & \multirow[b]{2}{*}{$\mathrm{Ri}_{B}{ }^{*}$} & \multirow[b]{2}{*}{ Median ND } & \multicolumn{3}{|c|}{$\%$ of obs with } & \multirow[b]{2}{*}{ IOA } & \multicolumn{3}{|c|}{ Linear regression } \\
\hline & & & $\begin{array}{c}-1<\mathrm{ND} \\
\leq 0\end{array}$ & $\begin{aligned} 0 & <\mathrm{ND} \\
& \leq 1\end{aligned}$ & $\mathrm{ND}>1$ & & Correl. & $\begin{array}{c}\text { Int. } \\
\left(\mathrm{W} \mathrm{m}^{-2}\right)\end{array}$ & Slope \\
\hline BT & All & -0.38 & 87.8 & 10.2 & 1.9 & 0.56 & 0.37 & -5.62 & 0.35 \\
\hline CCM2 & All & -0.41 & 90.0 & 8.4 & 1.6 & 0.55 & 0.38 & -4.96 & 0.35 \\
\hline CCM3 & All & -0.34 & 85.2 & 12.6 & 2.2 & 0.56 & 0.37 & -6.31 & 0.35 \\
\hline L79 & All & -0.10 & 58.6 & 36.9 & 4.5 & 0.58 & 0.34 & -9.02 & 0.46 \\
\hline MRF & All & -0.32 & 83.5 & 14.2 & 2.3 & 0.57 & 0.37 & -6.72 & 0.35 \\
\hline PW87 & All & -0.03 & 52.2 & 41.1 & 6.7 & 0.57 & 0.33 & -10.89 & 0.44 \\
\hline UKMO & All & -0.34 & 83.2 & 14.4 & 2.4 & 0.56 & 0.34 & -6.85 & 0.33 \\
\hline BT & $\leq 0.02$ & -0.39 & 88.5 & 9.1 & 2.4 & 0.57 & 0.41 & -4.85 & 0.41 \\
\hline CCM2 & $\leq 0.02$ & -0.40 & 89.1 & 8.9 & 2.0 & 0.57 & 0.41 & -4.67 & 0.41 \\
\hline CCM3 & $\leq 0.02$ & -0.37 & 87.0 & 10.3 & 2.8 & 0.58 & 0.40 & -5.08 & 0.42 \\
\hline L79 & $\leq 0.02$ & -0.15 & 63.3 & 32.0 & 4.7 & 0.62 & 0.40 & -6.98 & 0.57 \\
\hline MRF & $\leq 0.02$ & -0.37 & 86.8 & 10.3 & 2.8 & 0.58 & 0.40 & -5.14 & 0.42 \\
\hline PW87 & $\leq 0.02$ & -0.14 & 61.3 & 33.7 & 5.0 & 0.61 & 0.39 & -7.20 & 0.57 \\
\hline UKMO & $\leq 0.02$ & -0.37 & 86.9 & 10.3 & 2.8 & 0.58 & 0.40 & -5.15 & 0.42 \\
\hline BT & $>0.10$ & -0.84 & 100.0 & 0.0 & 0.0 & 0.33 & -0.21 & 19.45 & -0.09 \\
\hline CCM2 & $>0.10$ & -0.88 & 100.0 & 0.0 & 0.0 & 0.33 & -0.19 & 13.92 & -0.07 \\
\hline CCM3 & $>0.10$ & -0.58 & 92.2 & 7.8 & 0.0 & 0.35 & -0.33 & 44.42 & -0.22 \\
\hline L79 & $>0.10$ & -0.70 & 92.2 & 7.8 & 0.0 & 0.32 & -0.21 & 35.74 & -0.17 \\
\hline MRF & $>0.10$ & -0.35 & 82.5 & 16.5 & 1.0 & 0.43 & -0.31 & 47.70 & -0.24 \\
\hline PW87 & $>0.10$ & 0.07 & 45.6 & 48.5 & 5.8 & 0.47 & -0.37 & 73.18 & -0.37 \\
\hline UKMO & $>0.10$ & -0.71 & 97.1 & 2.9 & 0.0 & 0.33 & -0.24 & 31.82 & -0.15 \\
\hline
\end{tabular}

* Calculated statistics for cases with observed $\mathrm{SH} \leq-10 \mathrm{~W} \mathrm{~m}^{-2} ; n=1695$ for all $\mathrm{Ri}_{B,} n=1199$ for $\mathrm{Ri}_{B} \leq 0.02$, and $n=103$ for $\mathrm{Ri}_{b}$ $>0.10$.

cases). Based on the best-fit line it is found that the SL parameterizations tend to overestimate $u_{*}$ when the observed value of $u_{*}<0.2 \mathrm{~m} \mathrm{~s}^{-1}$ and underestimate $u_{*}$ when the observed value of $u_{*}$ is larger. The calculated index of agreement values is consistent with the linear regression correlation coefficients.

In contrast, the seven SL parameterizations poorly represent $u_{*}$ for the strong static stability cases. For these cases, the distribution of $\mathrm{ND}_{u *}$ is strongly skewed toward negative values (Figs. 2e and 2f), with median $\mathrm{ND}_{u *} \leq-0.30$, and more than $95 \%$ of the cases considered in this static stability class have $\mathrm{ND}_{u *} \leq 0$ (Table 2 ). The linear regression of this subset of the data reveals minimal skill for the seven SL parameterizations, with the correlation coefficient near 0 , and index of agreement values near 0.3 . These results would appear to imply that the stability correction term becomes too large as $\mathrm{Ri}_{B}$ increases, but similar errors appear in the PW87 SL, which does not employ a stability correction term. It therefore appears that the SL for the strong stability cases is poorly described by Monin-Obukhov similarity theory, or that the SL is shallower than the 3.5-4.9-m observation height, as was discussed in King (1990). The presence of wave activity for the strong static stability cases (King 1993) may also contribute to the poor comparison of the calculated and observed turbulent fluxes, as this physical process is not represented by any of the SL parameterizations evaluated. Further development of SL parameterizations for use in strongly static stability conditions needs to be explored.

\section{2) Comparison of obSERVED AND CALCUlAted SENSIBLE HEAT FLUX VALUES}

Comparison of the observed $\mathrm{SH}$ fluxes with the calculated SH fluxes is limited to cases for which the observed magnitude of $\mathrm{SH} \geq 10 \mathrm{~W} \mathrm{~m}^{-2}$, reducing the number of hourly observations from 3963 to 1768. This restriction is imposed on the dataset because time series of the observed $\mathrm{SH}$ values are very scattered when the observed magnitude of $\mathrm{SH}<10 \mathrm{~W} \mathrm{~m}^{-2}$. The data that are excluded are also most susceptible to contamination from wave activity (strong static stability and small turbulent fluxes).

Before the results of the SH flux comparison are discussed further, it should be noted that values of $\mathrm{ND}_{\mathrm{SH}}$ $<-1$ indicate that the calculated and observed $\mathrm{SH}$ fluxes are of opposite sign. Since only cases in which the potential temperature is observed to increase with height are considered, the calculated $\mathrm{SH}$ fluxes are always negative (directed from the atmosphere to the surface) (Table 1). Therefore the cases in which $\mathrm{ND}_{\mathrm{SH}}<-1$ indicate situations in which the observed SH flux is directed from the surface to the overlying atmosphere, against the observed potential temperature gradient. This situation occurs in $73(4.1 \%)$ of the hourly observations in the dataset. This apparently anomalous behavior may be accounted for by the presence of a low-level temperature maximum between the surface and the height of the ultrasonic thermometer [as discussed in de la Casinière (1974), Halberstam and Schieldge (1981), and King and Anderson (1994)], may be caused by contributions to 
the SH flux from wave activity, or may be due to errors in the observed SH fluxes. Statistics in Table 3 are calculated only for those cases in which the observed $\mathrm{SH}$ flux is directed from the atmosphere to the surface, down the observed mean potential temperature gradient.

The results in Fig. 3 and Table 3 indicate that the SL parameterizations are less accurate in representing the SH flux than $u_{*}$. The frequency distribution of $\mathrm{ND}_{\mathrm{SH}}$ is broader than that for $\mathrm{ND}_{u *}$, and the median $\mathrm{ND}_{\mathrm{SH}}$ is shifted toward more negative values.

For the entire dataset and the cases with $\mathrm{Ri}_{B} \leq 0.02$ the frequency distribution of $\mathrm{ND}_{\mathrm{SH}}$ is nearly identical for the BT, CCM2, CCM3, MRF, and UKMO SL parameterizations (Figs. 3a-d). For these parameterizations the median $\mathrm{ND}_{\mathrm{SH}}$ is $<-0.3$, and more than $83 \%$ of the calculated SH fluxes have $\mathrm{ND}_{\mathrm{SH}}$ between -1 and 0 (Table 3). This indicates that the magnitude of the downward-directed SH flux in these parameterizations is an underestimation of the magnitude of the observed SH flux for a majority of the cases considered. This underestimation of the downward-directed $\mathrm{SH}$ flux is less severe for the L79 and PW87 SL parameterizations, with the median $\mathrm{ND}_{\mathrm{SH}}$ ranging from -0.15 to -0.03 . Still more than $50 \%$ of the cases considered have $\mathrm{ND}_{\mathrm{SH}}$ between -1 and 0 for all of the parameterizations (Table 3).

The linear regression analysis indicates that the calculation of SH is less skillful compared to that of $u_{*}$ for the seven SL parameterizations evaluated. The correlation coefficients range from 0.33 to 0.41 for the calculated SH fluxes for the entire dataset and the weak static stability cases. For a given set of observations the correlation coefficients are generally quite similar for all of the SL parameterizations. This is also true for the calculated values of the index of agreement (Table 3). The best-fit line for the calculated SH fluxes intersects the 1:1 line between the observed and calculated $\mathrm{SH}$ fluxes at values of -7.6 to $-10.3 \mathrm{~W} \mathrm{~m}^{-2}$ for the BT, CCM2, CCM3, MRF, and UKMO SL parameterizations and values of -16.2 to $-19.4 \mathrm{~W} \mathrm{~m}^{-2}$ for the $\mathrm{L} 79$ and PW87 SL parameterizations. For observed downward SH fluxes larger than these values the SL parameterizations tend to underestimate the downward-directed SH flux.

Relative to the other static stability cases, the frequency distribution of $\mathrm{ND}_{\mathrm{SH}}$ is broader and skewed toward more negative values for the strong static stability cases $\left(\mathrm{Ri}_{B}>0.10\right)$. More than $80 \%$ of the cases considered have $\mathrm{ND}_{\mathrm{SH}}$ between -1 and 0 , except for the PW87 SL parameterization, and a larger percent of the cases have $\mathrm{ND}_{\mathrm{SH}}<-1$, indicating that the observed and calculated SH fluxes are of opposite sign. The median $\mathrm{ND}_{\mathrm{SH}} \leq-0.7$ for the BT, CCM2, L79, and UKMO SL parameterizations; while the CCM3, MRF, and PW87 SL parameterizations have median $\mathrm{ND}_{\mathrm{SH}}$ values closer to zero.

The correlation coefficients from the linear regression analysis for these data are negative for all of the SL parameterizations, indicating that the SH fluxes calculated with the SL parameterizations are inversely correlated with the observed SH fluxes. The index of agreement values for these cases are also low, indicative of the reduced skill in predicting the SH fluxes for the strong static stability cases. These strong static stability cases are most likely to contain contributions to the $\mathrm{SH}$ flux from wave activity, which is not represented in the Monin-Obukhov similarity theory based SL parameterizations evaluated in this paper.

\section{c. Discussion of surface layer parameterization verification results}

The results presented in the last two subsections indicate that in general the SL parameterizations that are in wide use in numerical models adequately predict $u_{*}$ (except for the strongest static stability class considered), but can significantly underestimate the magnitude of the downward-directed SH flux in the stably stratified SL. Also, the predicted values of $u_{*}$ are closely correlated with the observed values (again, except for the strong static stability cases), while there is more scatter between the predicted and observed SH flux values.

Since the calculated SH fluxes are found to be biased, additional analysis into the source of this error is conducted. To aid in this analysis the SH flux is represented in the general form

$$
\overline{w^{\prime} \theta^{\prime}}=-C_{H} V\left(\theta_{a}-\theta_{g}\right)
$$

where

$$
\begin{aligned}
C_{H} & =\frac{C_{H, N} F_{H}\left(\mathrm{Ri}_{B}\right)}{\operatorname{Pr}} \text { and } \\
C_{H, N} & =\frac{k^{2}}{\left[\ln \left(\frac{z}{z_{0}}\right)\right]\left[\ln \left(\frac{z}{z_{H}}\right)\right]} .
\end{aligned}
$$

Here, $C_{H}$ is the transfer coefficient, $C_{H, N}$ is the neutral transfer coefficient from SL similarity theory, $F_{H}\left(\mathrm{Ri}_{B}\right)$ is a stability correction function, and $\operatorname{Pr}$ is the turbulent Prandtl number (the ratio of the eddy diffusivities of heat and momentum).

Two potential sources of error in the calculated $\mathrm{SH}$ fluxes are inappropriately specified values of $z_{0}$ or $z_{H}$, or errors in $F_{H}$. In order to evaluate these possible errors, $F_{H}$ is calculated from the observed SH fluxes $\left(F_{H, \text { obs }}\right)$ using

$$
F_{H, \mathrm{obs}}=\frac{\overline{w^{\prime} \theta^{\prime}} \operatorname{Pr}}{C_{H, N} V\left(\theta_{a}-\theta_{g}\right)} .
$$

As $\mathrm{Ri}_{B} \rightarrow 0$ (the neutral limit), $F_{H, \text { obs }}$ should be equal to unity. If the value of $F_{H, \text { obs }}$ differs from unity in the neutral limit then it can be concluded that $C_{H, N}$ (i.e., $z_{0}$ or $z_{H}$ ) is specified incorrectly for the set of measurements. The value of $F_{H, \text { obs }}$ in the neutral limit is estimated as the median value of $F_{H, \text { obs }}$ for all observations with 
$\mathrm{Ri}_{B} \leq 0.01$, and is equal to 1.63 when $\mathrm{Pr}$ is assumed to be equal to unity (the same assumption that is made in the BT, CCM2, CCM3, MRF, and UKMO SL parameterizations) and is equal to 1.21 when $\mathrm{Pr}$ assumed to be equal to 0.74 (the same assumption that is made in the L79 and PW87 SL parameterizations). Based on these values of $F_{H \text { obs }}$ in the neutral limit, it can be concluded that $C_{H, N}$ is too small for the dataset being considered and that either the value of $z_{0}$ and/or $z_{H}$ is too small.

For the Halley observation site, estimates of $z_{0}$ from other observational campaigns range from $5.6 \times 10^{-5}$ to $1.1 \times 10^{-4} \mathrm{~m}$ (King 1990; King and Anderson 1994). Since the value of $z_{0}$ that is being used in the current study is at the upper range of values previously quoted for this site, and the calculated values of $u_{*}$ are in reasonably good agreement with the observed $u_{*}$ values when calculated with this value of $z_{0}$, it is assumed that the errors in $C_{H, N}$ are due to errors in the value of $z_{H}$. The task is then reduced to calculating a value of $z_{H}$ that will give $F_{H \text {,obs }}$ equal to unity in the neutral limit, for the observed SH fluxes. The value of $z_{H}$ that satisfies this criterion is $8.0 \times 10^{-3} \mathrm{~m}$ when a value of $\operatorname{Pr}=1$ is assumed, and $9.0 \times 10^{-4} \mathrm{~m}$ when a value of $\mathrm{Pr}=$ 0.74 is assumed.

Both values of $z_{H}$ determined from $F_{H \text {,obs }}$ in the neutral limit are greater than the value of $z_{0}$ that was assumed for this site. Theoretical predictions indicate that $z_{H}$ should be less than $z_{0}$ for the aerodynamically rough regime in which the current measurements were made (Andreas 1987; King and Anderson 1994). Alternately, King and Anderson (1994) estimated that $z_{H}$ ranged from $6 \times 10^{-3}$ to $1.4 \times 10^{-1} \mathrm{~m}$ for SL measurements made at Halley in 1991. These estimates of $z_{H}$ are much greater than the value of $z_{0}$ at this site, and are similar to or larger than the values of $z_{H}$ estimated with the current dataset. Despite the differences between the current values of $z_{H}$, which are estimated from an analysis of $F_{H \text {,obs }}$ in the neutral limit, and previously cited values of this quantity, it can be stated that the values of $z_{H}$, calculated as described above, are required to force the $\mathrm{SL}$ parameterizations to agree with the observed $\mathrm{SH}$ fluxes in the neutral limit. Since all of the parameterizations that are evaluated in this paper are based on Monin-Obukhov similarity theory, which does not include a representation of heat fluxes due to gravity waves, the larger value of $z_{H}$, determined empirically from the analysis of $F_{H \text {,obs }}$ in the neutral limit, may be an artificial solution that compensates for the unrepresented fluxes caused by gravity waves. Therefore the general applicability of these larger values of $z_{H}$ to other locations or datasets is not clear, and needs to be evaluated using additional SL measurements over snow surfaces.

Additionally, the better performance of the PW87 SL parameterization, compared to the other SL parameterizations evaluated in this paper (Table 3) may be due, in part, to the larger SH flux calculated by this param-
TABLE 4. Median $\mathrm{ND}_{\mathrm{SH}}$, IOA, and correl. for cases in which $z_{H} \neq$ $z_{0}$. A value of $z_{H}=8.0 \times 10^{-3} \mathrm{~m}$ is used for the calculations with the BT, CCM2, CCM3, MRF, and UKMO SL parameterizations. A value of $z_{H}=9.0 \times 10^{-4} \mathrm{~m}$ is used for the calculations with the L79 and PW87 SL parameterizations. Here, SL refers to the surface layer parameterization used to calculate the turbulent fluxes and $\mathrm{Ri}_{B}$ denotes the range of bulk Richardson numbers considered when calculating the statistics.

\begin{tabular}{lcccr}
\hline \hline SL & $\mathrm{Ri}_{B}{ }^{*}$ & Median $\mathrm{ND}_{\mathrm{SH}}$ & $\mathrm{IOA}$ & Correl. \\
\hline BT & $\mathrm{All}$ & 0.04 & 0.58 & 0.37 \\
CCM2 & $\mathrm{All}$ & 0.00 & 0.60 & 0.39 \\
CCM3 & $\mathrm{All}$ & -0.05 & 0.63 & 0.40 \\
L79 & $\mathrm{All}$ & 0.12 & 0.54 & 0.34 \\
MRF & $\mathrm{All}$ & 0.07 & 0.59 & 0.39 \\
PW87 & $\mathrm{All}$ & 0.15 & 0.54 & 0.34 \\
UKMO & $\mathrm{All}$ & 0.12 & 0.54 & 0.34 \\
BT & $\leq 0.02$ & 0.03 & 0.60 & 0.41 \\
CCM2 & $\leq 0.02$ & 0.01 & 0.61 & 0.42 \\
CCM3 & $\leq 0.02$ & -0.02 & 0.63 & 0.42 \\
L79 & $\leq 0.02$ & 0.06 & 0.58 & 0.40 \\
MRF & $\leq 0.02$ & 0.04 & 0.59 & 0.41 \\
PW87 & $\leq 0.02$ & 0.05 & 0.58 & 0.40 \\
UKMO & $\leq 0.02$ & 0.06 & 0.58 & 0.40 \\
BT & $>0.10$ & -0.73 & 0.22 & -0.10 \\
CCM2 & $>0.10$ & -0.80 & 0.12 & -0.10 \\
CCM3 & $>0.10$ & -0.42 & 0.58 & 0.09 \\
L79 & $>0.10$ & -0.63 & 0.50 & -0.11 \\
MRF & $>0.10$ & -0.18 & 0.79 & 0.35 \\
PW87 & $>0.10$ & 0.17 & 0.82 & 0.24 \\
UKMO & $>0.10$ & -0.52 & 0.44 & -0.10 \\
\hline
\end{tabular}

* Calculated statistics for cases with observed $\mathrm{SH} \leq-10 \mathrm{~W} \mathrm{~m}^{-2}$.

eterization, for a given set of conditions, due to the neglected stability correction function for $u_{*}$ (see Table 1 ). This physically unrealistic representation of $u_{*}$, and thus $\mathrm{SH}$, in the PW87 parameterization could then compensate for the neglected gravity wave heat flux in the parameterization leading to better agreement with the observed SH fluxes for inappropriate reasons.

Using the newly calculated values of $z_{H}$ in the SL parameterizations greatly reduces the bias in the calculated $\mathrm{SH}$ fluxes. Table 4 lists the median $\mathrm{ND}_{\mathrm{SH}}$, index of agreement, and correlation coefficient for the seven SL parameterizations when a value of $z_{H}=8.0 \times 10^{-3}$ $\mathrm{m}$ is used in the BT, CCM2, CCM3, MRF, and UKMO SL parameterizations and when a value of $z_{H}=9.0 \times$ $10^{-4} \mathrm{~m}$ is used in the L79 and PW87 SL parameterizations. From the values listed in Table 4 it can be seen that the tendency for the SL parameterizations to underestimate the downward-directed $\mathrm{SH}$ flux, for cases with $\mathrm{Ri}_{B} \leq 0.02$, is greatly reduced, although there is still a large bias in the calculated $\mathrm{SH}$ fluxes for cases in which $\mathrm{Ri}_{B}>0.10$. There is a large improvement in the predictive skill of the MRF and PW87 SL parameterizations (and to a lesser extent the CCM3 SL parameterization) for the strong static stability data, as indicated by the change in the index of agreement and correlation coefficient values between Tables 3 and 4 . For the other SL parameterizations and static stability classes there is little change in the index of agreement or correlation coefficient when $z_{H}$ is changed. 

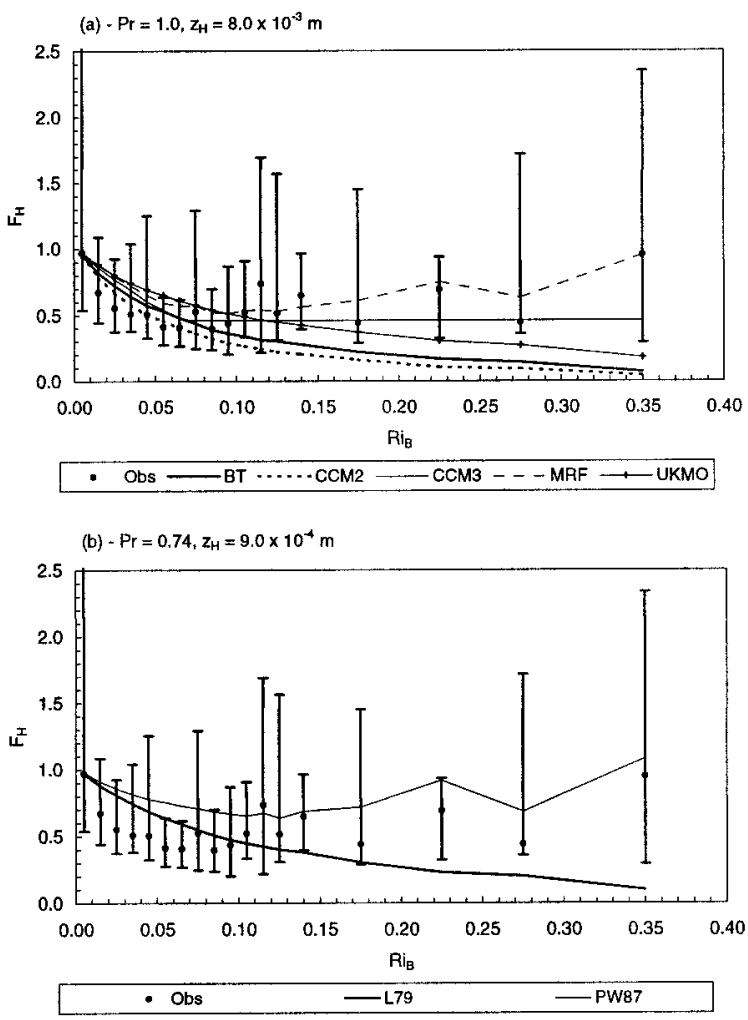

FIG. 4. Comparison of $F_{H}\left(\mathrm{Ri}_{B}\right)$ from seven SL parameterizations, with the median $F_{H}$ calculated from the observed SH fluxes over selected $\mathrm{Ri}_{B}$ intervals (see the text for a discussion of the calculation of $F_{H}$ from the observations). Here, $F_{H}$ is calculated from the observations assuming $\operatorname{Pr}=1.0$ and $z_{H}=8.0 \times 10^{-3} \mathrm{~m}$ in (a) and assuming $\operatorname{Pr}=0.74$ and $z_{H}=9.0 \times 10^{-4} \mathrm{~m}$ in (b). Error bars indicate the 0.1 and 0.9 percentile values of $F_{H}$ calculated from the observations.

In order to explore these results, the values of $F_{H}$ as a function of $\mathrm{Ri}_{B}$ for the seven SL parameterizations are plotted in Fig. 4 along with the median values of $F_{H, \text { obs }}$. The median values of $F_{H, \text { obs }}$ plotted in Fig. 4 are calculated over intervals of $\mathrm{Ri}_{B}$ of 0.01 for $0 \leq \mathrm{Ri}_{B} \leq$ $0.13,0.02$ for $0.13<\mathrm{Ri}_{B} \leq 0.15$, and 0.05 for $0.15<$ $\mathrm{Ri}_{B} \leq 0.3$. The median of all observations with $\mathrm{Ri}_{B}>$ 0.3 is calculated to produce the data point plotted at $\mathrm{Ri}_{B}$ $=0.35$ in Fig. 4 . The error bars plotted for the observed values of $F_{H . \text { obs }}$ represent the 0.1 and 0.9 percentile values of $F_{H, \text { obs }}$ over each $\mathrm{Ri}_{B}$ interval. In Fig. 4 a, the values of $F_{H, \text { obs }}$ that are plotted are calculated with an assumed value of $\operatorname{Pr}=1$ and $z_{H}=8.0 \times 10^{-3} \mathrm{~m}$, while in Fig. $4 \mathrm{~b}$ the values of $F_{H, \text { obs }}$ that are plotted are calculated with an assumed value of $\operatorname{Pr}=0.74$ and $z_{H}=9.0 \times$ $10^{-4} \mathrm{~m}$.

From Fig. 4 it should be noted that $F_{H, \text { obs }}$ decreases more rapidly than the value of $F_{H}$ calculated from all of the SL parameterizations for $\mathrm{Ri}_{B}<0.05$, although the CCM2 and BT SL parameterizations most closely match the rapid decrease of $F_{H, \text { obs }}$.

For values of $\mathrm{Ri}_{B}>0.05, F_{H, \text { obs }}$ is nearly constant, and actually begins to increase for $\mathrm{Ri}_{B}>0.20$. This nearly constant value of $F_{H, \text { obs }}$ with increasing $\mathrm{Ri}_{B}$, is not con- sistent with the expected decay of turbulence with increasing $\mathrm{Ri}_{B}$, and may reflect an increasing contribution to the measured $\mathrm{SH}$ flux from gravity wave activity as the stability increases. Over this $\mathrm{Ri}_{B}$ interval the BT, CCM2, L79, and UKMO SL parameterization $F_{H}$ values become smaller than $F_{H, \text { obs }}$. At even larger values of $\mathrm{Ri}_{B}$ only the values of $F_{H}$ from the CCM3, MRF, and PW87 SL parameterizations are within the range of values of $F_{H, \text { obs }}$. This is consistent with the $\mathrm{ND}_{S H}$ values listed in Table 4 for these SL parameterizations being closer to zero than the other SL parameterizations and helps explain the improved predictive skill of these SL parameterizations, for $\mathrm{Ri}_{B}>0.10$. The comparison between $F_{H, \text { obs }}$ and $F_{H}$ from the SL parameterizations for large $\mathrm{Ri}_{B}$ values should not be considered to be a definitive analysis, since only $6 \%$ of the total observations in the current dataset are for conditions in which $\mathrm{Ri}_{B}>0.10$, and wave activity may have contributed to the large $F_{H \text { obs }}$ for these cases. Additional SL observations for conditions of large static stability are required for a thorough verification of these preliminary findings.

Based on the results in this section it is found that better agreement between the observed and calculated SH fluxes could be achieved if $z_{H}>z_{0}$ is used when calculating the fluxes. Specifically the tendency for all of the SL parameterizations to underestimate the downward-directed $\mathrm{SH}$ fluxes for low $\mathrm{Ri}_{B}$ situations is removed, but significant discrepancies still exist between the calculated and observed $\mathrm{SH}$ fluxes for large $\mathrm{Ri}_{B}$ conditions, for some of the SL parameterizations.

\section{d. Applicability of the results from Halley to the rest of the Antarctic continent}

Since observations from only one location in the Antarctic are considered, it is necessary to evaluate whether the conclusions drawn from these data are applicable to other regions in the Antarctic. Some issues that need to be considered include the coastal location, the lack of katabatic winds, and the nearly continuous presence of wave activity in the boundary layer at Halley.

It is well known that the low-level temperature inversion strength increases as one progresses from the coast of Antarctica to the far interior of the continent (Phillpot and Zillman 1970). The average wintertime inversion strength is roughly $5 \mathrm{~K}$ near the coast and increases to over $25 \mathrm{~K}$ in the interior regions of Antarctica.

Another well-documented aspect of the near-surface climate of Antarctica is the katabatic wind regime, which affects all regions of the continent that have an appreciable ice slope (King and Turner 1997). The strength of the katabatic flow increases as the terrain slope increases, and given the ice dome topography of the continent the katabatic winds are strongest along the periphery of the continent and weakest in the interior. Over the ice shelves adjacent to Antarctica the terrain slopes tend to be quite shallow (approximately 0.002 at 
Halley) and the drainage flow is weak (except in localized areas of katabatic outflow from the ice slopes, such as over the Ross Ice Shelf).

The distribution of the low-level temperature inversion strength and katabatic wind intensity determines the intensity of turbulence that exists at a given location, and can be quantified with the parameter $\mathrm{Ri}_{B}$, which is defined in (1). The observed distribution of wind and temperature in the Antarctic causes high $\mathrm{Ri}_{B}$ conditions to persist in the far interior of the continent with smaller values of $\mathrm{Ri}_{B}$ more common near the coast. Over the adjacent ice shelves the weaker temperature inversion and the presence of weak topographically forced flows, or synoptically driven winds, also results in relatively small values of $\mathrm{Ri}_{B}$. To illustrate this point observations of $\mathrm{Ri}_{B}$ at Halley are compared to those at Mizuho Station $\left[70.7^{\circ} \mathrm{S}, 44.3^{\circ} \mathrm{E} ; 2230 \mathrm{~m}\right.$ above sea level (ASL)] and Plateau Station $\left(79.2^{\circ} \mathrm{S}, 40.5^{\circ} \mathrm{E} ; 3625 \mathrm{~m}\right.$ ASL). These three stations are taken to represent the range of conditions from the Antarctic coastal environment to intermediate interior locations to far interior locations, respectively. In the Halley dataset used in this paper $\mathrm{Ri}_{B}$ is $\leq 0.02$ for approximately $70 \%$ of the observations, while at Mizuho more than $90 \%$ of the SL observations made between June and December 1972 have $\mathrm{Ri}_{B}<0.02$ (Sasaki 1979). The observations made at Plateau Station during 1967 have $\mathrm{Ri}_{B}<0.2$ approximately $50 \%$ of the time (Lettau et al. 1977). Based on this limited comparison, it appears that the observations at Halley may be representative of some static features over much of the Antarctic continent, except for the far interior locations. The difference in the static stability at the far interior locations, compared to that found at Halley, is likely to be significant, and makes conclusions about the performance of SL parameterizations in the interior of the continent speculative at this time. Given the poor performance of the SL parameterizations for the strong static stability cases evaluated in this paper, it is expected that the SL parameterizations currently being used are not representing the surface fluxes in the interior of the continent in a realistic manner. Comparison of the SL parameterizations with direct turbulence measurements made in the interior of the continent are needed to fully evaluate the extent of this problem.

Another item of concern is the presence of wavelike motions in the stable boundary layer at Halley and the effect that these waves have on the measured turbulent fluxes. King (1993) addressed this topic, and states that weak to moderate wave activity is present at Halley whenever the boundary layer is stably stratified. He found that these waves tend to increase the energy contained in horizontal motions, but do not increase the energy associated with vertical motions, and that the waves do not make a significant contribution to the turbulent momentum stress. Larger-amplitude waves occur much less frequently at Halley, and clearly alter the momentum stress. These large-amplitude events are observed only during periods of strong static stability, when the turbulent motions are weakest. The data used to evaluate the SL parameterizations had the weak flux cases removed to help minimize the impact of large amplitude wave activity on the results. Still, wave activity may help to explain the poor performance of the SL parameterizations for the strong static stability cases considered in this study. Further work needs to be done to clarify the relationship between waves in the stable boundary layer and their impact on turbulence, and methods to improve SL parameterizations for these conditions.

Observations of wave activity from other sites in the Antartic are limited, although it is likely that these motions are present in the boundary layer over much of the continent (being generated by shear in the katabatic flow or by flow over irregular surfaces, such as sastrugi fields). King's finding that large-amplitude wave events were confined to the strongest static stability conditions implies that wave motions may play a greater role in heat and momentum transports in the far interior of the continent, compared to the near-coastal regions. Again, this issue awaits further observational studies in the interior of the Antarctic continent during the austral winter.

In concluding this section it is important to remember that despite the differences in the near-surface environment at Halley compared to other locations over the Antarctic continent, there are still many important similarities, including the lack of a pronounced diurnal cycle, and prolonged periods of no incoming solar radiation. Also, in contrast to stable boundary layers in midlatitude locations, which commonly form in the remnants of the daytime mixed layer, the stable boundary layer in the Antarctic is contained within a stably stratified lower troposphere (King and Turner 1997).

In the next section it is assumed that the findings presented thus far are representative of the entire Antarctic continent. The importance of these findings in terms of idealized simulations of Antarctic katabatic winds is explored and related to larger scale climatic implications.

\section{Idealized katabatic wind sensitivity studies \\ a. Model description}

The idealized katabatic wind simulations that are discussed below are performed with the PSU-NCAR MM5 (version 2.9), described in detail by Dudhia (1993) and Grell et al. (1994). A brief description of the model configuration used for this study is presented below.

The MM5 is run in a nonhydrostatic mode, since this model formulation is less prone to truncation errors in the calculation of the horizontal pressure gradient force over steeply sloping terrain (Dudhia 1993). The key physical parameterizations employed include the 1.5order turbulence closure routine of Burk and Thompson (1989) to describe turbulence above the SL. The tur- 


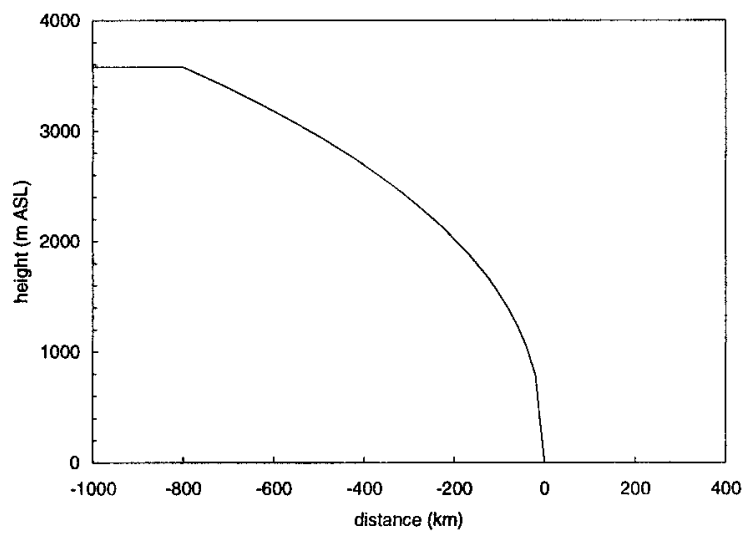

FIG. 5. Model terrain used for 2D sensitivity experiments.

bulence in the SL is parameterized with the seven SL parameterizations described in previous sections of this paper. Additional comments on their configuration for the sensitivity studies are given below. Radiative transfer in the atmosphere is parameterized with the CCM2 radiation parameterization described in Hack et al. (1993). The effects of shortwave radiation are neglected in order to represent austral winter conditions, when the katabatic flow is strongest. The model is used in a dry mode such that cloud and precipitation processes are neglected, as is the transfer of moisture between the surface and the overlying atmosphere. The effect of moisture on the transfer of radiation through the atmosphere is simulated by assuming a fixed relative humidity of $30 \%$ at all grid points within the model domain. It is found that varying the relative humidity has little effect on the simulated katabatic flow, given the low temperatures present in the model domain, and thus the small absolute amount of water vapor present in the atmosphere.

The model is used in a $2 \mathrm{D}$ mode, and the model domain encompasses $1400 \mathrm{~km}$ in the horizontal direction, with a horizontal grid spacing of $20 \mathrm{~km}$. The horizontal domain is partitioned into a $1000-\mathrm{km}$ section that includes terrain representative of the ice topography along the $90^{\circ} \mathrm{E}$ meridian of Antarctica. This terrain is specified with a power law fit to the Antarctic topography as described in Parish and Waight (1987). The remaining $400 \mathrm{~km}$ of the model domain is assumed to be ice-covered ocean, thereby neglecting the effects of open water on the evolution of the katabatic flow. The model terrain used in this study is shown in Fig. 5.

In the vertical direction the model employs 25 sigma levels that extended from the surface to a fixed pressure of $25000 \mathrm{~Pa}$ at the model top. The sigma levels are spaced unevenly in the vertical, with the highest resolution near the surface. The lowest sigma level is located at a height of $14 \mathrm{~m}$ above ground level (AGL), with seven sigma levels located within $210 \mathrm{~m}$ of the surface. This model vertical grid representation is chosen to more accurately represent the processes occurring in the katabatic layer, while keeping the number of vertical levels similar to that used in general circulation models and operational numerical weather prediction models. Additional simulations with increased vertical resolution (and 34 sigma levels) are also performed to evaluate the impact that the height of the lowest model level has on the simulated surface turbulent fluxes. For these simulations the lowest model level is located at a height of $3 \mathrm{~m}$ AGL, similar to the observation height for the Halley dataset.

All simulations presented in this paper are initialized with no ambient horizontal temperature gradient. The initial temperature profile has a constant lapse rate, from the surface to the model top, and is similar to the temperature profile given by Schwerdtfeger (1984, see Fig. 6.9) for Byrd Station, and is representative of conditions prior to the onset of rapid surface cooling during the austral winter period.

For all the simulations a strong low-level temperature inversion quickly develops in response to radiative cooling of the atmosphere and the turbulent transfer of heat from the atmosphere to the radiatively cooled surface. This inversion then leads to the formation of a horizontal pressure gradient force that allows the katabatic flow to develop. The katabatic circulation is well established within $12 \mathrm{~h}$ of the start of the simulations and is in a near-steady state by $24 \mathrm{~h}$. All the results that are presented in this paper are taken from the model simulations $24 \mathrm{~h}$ after they were started.

\section{b. Results of the katabatic wind sensitivity simulations}

Based on the results presented in section 3, sensitivity simulations using the CCM2 and PW87 SL parameterizations are presented. These parameterizations are selected for the sensitivity studies because they are representative of the range of median $\mathrm{ND}_{u *}$ and $\mathrm{ND}_{\mathrm{SH}}$ for the SL parameterizations evaluated in this study (Tables 2, 3, and 4). Furthermore, the simulations presented in this section focus solely on errors in the calculated $\mathrm{SH}$ flux, while neglecting errors in the calculated $u_{*}$. This approach is reasonable given the much smaller $\mathrm{ND}_{u} *$ compared to $\mathrm{ND}_{\mathrm{SH}}$ discussed in section 3 .

Analysis of errors due to an inappropriately specified value of $z_{H}$, as well as errors in the form of $F_{H}\left(\mathrm{Ri}_{B}\right)$ are explored. Also, the impact that the depth of the SL in the model, determined by the height of the lowest model level, has on the simulated katabatic flows is evaluated.

To address the first issue pairs of simulations are conducted in which $z_{H}=z_{0}=1.1 \times 10^{-4} \mathrm{~m}$ is assumed for one simulation of the pair while the optimal value of $z_{H}$ (determined in section $3 \mathrm{c}$ ), with $z_{0}$ left unchanged, is used for the second simulation of the pair. The effect of errors in the specification of $F_{H}\left(\mathrm{Ri}_{B}\right)$ in the SL parameterizations is addressed by comparing the results from the CCM2 and PW87 sensitivity experiments, since the form of $F_{H}\left(\mathrm{Ri}_{B}\right)$ in these parameterizations 
TABLE 5. List of the sensitivity experiment names (name), surface layer parameterization used (SL), scalar roughness length for heat $\left(z_{H}\right)$, ambient geostrophic wind speed $\left(V_{g}\right)$, and height of the lowest model level $\left(z_{L}\right)$.

\begin{tabular}{lccrc}
\hline \hline \multicolumn{1}{c}{ Name } & SL & $z_{H}(\mathrm{~m})$ & $\begin{array}{c}V_{g} \\
\left(\mathrm{~m} \mathrm{~s}^{-1}\right)\end{array}$ & $\begin{array}{c}z_{L} \\
(\mathrm{~m} \mathrm{AGL})\end{array}$ \\
\hline CCM2.0 & CCM2 & $1.1 \times 10^{-4}$ & 0.0 & 14 \\
CCM2.zh.0 & CCM2 & $8.0 \times 10^{-3}$ & 0.0 & 14 \\
CCM2.10 & CCM2 & $1.1 \times 10^{-4}$ & 10.0 & 14 \\
CCM2.zh.10 & CCM2 & $8.0 \times 10^{-3}$ & 10.0 & 14 \\
PW87.0 & PW87 & $1.1 \times 10^{-4}$ & 0.0 & 14 \\
PW87.zh.0 & PW87 & $9.0 \times 10^{-4}$ & 0.0 & 14 \\
PW87.10 & PW87 & $1.1 \times 10^{-4}$ & 10.0 & 14 \\
PW87.zh.10 & PW87 & $9.0 \times 10^{-4}$ & 10.0 & 14 \\
PW87.dz.0 & PW87 & $1.1 \times 10^{-4}$ & 0.0 & 3 \\
PW87.dz.10 & PW87 & $1.1 \times 10^{-4}$ & 10.0 & 3 \\
\hline
\end{tabular}

encompasses the observed range of $F_{H}\left(\mathrm{Ri}_{B}\right)$ (Fig. 4). Finally, simulations with the lowest model level located at $3 \mathrm{~m}$ AGL are compared to simulations in which the lowest model level is located at $14 \mathrm{~m}$ AGL to evaluate the model sensitivity to the assumed depth of the SL.

The simulations are initialized with a range of ambient geostrophic wind speeds to evaluate if the sensitivity to errors in the SL parameterizations is dependent on the ambient wind speed (the geostrophic flow is directed across the terrain slope such that the pressure gradient force is directed down the ice slope). Table 5 lists the names of the numerical experiments discussed in this section, the SL parameterization employed, the value of $z_{H}$ used to calculate the SH flux, the ambient geostrophic wind speed, and the height of the lowest model level.

Two aspects of the sensitivity simulations are addressed in the following two subsections. The first area of interest deals with differences in the low-level flow and the intensity of the katabatic circulation. Specifically the cooling, downslope wind speed, and katabatic layer mass transport for pairs of simulations are compared. The second area of interest focuses on the role of turbulent heat transfer to the surface and its relative contribution to the thermodynamic state of a deep layer of the atmospheric column. This effect is evaluated by calculating the fraction of the diabatic cooling in an atmospheric column that results from the simulated turbulent cooling rates in the sensitivity simulations.

\section{1) Intensity of the KATABAtic CiRCULATION}

The maximum magnitude differences in the downslope wind speed and cooling, after $24 \mathrm{~h}$ of model integration, for the pairs of simulations are listed in Table 6. For reference, cross sections of the downslope wind speed and 24-h potential temperature change for the unmodified CCM2 and PW87 simulations are shown in Fig. 6.

Considering the $z_{H}$ sensitivity cases first, it should be noted from the data in Table 6 that the PW87 SL simulations show much less sensitivity to changes in $z_{H}$
TABLE 6. Maximum magnitude difference in the downslope wind speed $(\Delta v)$ and potential temperature $(\Delta \theta)$ between the pairs of sensitivity experiments. The simulation names for the cases being compared are listed in the first column of the table.

\begin{tabular}{lcc}
\hline \multicolumn{1}{c}{ Cases } & $\Delta v\left(\mathrm{~m} \mathrm{~s}^{-1}\right)$ & $\Delta \theta(\mathrm{K})$ \\
\hline CCM2.0-CCM2.zh.0 & -2.1 & 5.5 \\
PW87.0-PW87.zh.0 & -0.1 & 0.4 \\
CCM2.10-CCM2.zh.10 & -2.1 & 3.2 \\
PW87.10-PW87.zh.10 & 0.3 & 0.4 \\
CCM2.zh.0-PW87.zh.0 & -7.3 & 20.6 \\
CCM2.zh.10-PW87.zh.10 & -3.3 & 6.2 \\
PW87.dz.0-PW87.0 & -3.6 & 10.2 \\
PW87.dz.10-PW87.10 & -3.3 & 11.5 \\
\hline
\end{tabular}

than the CCM2 SL simulations. The maximum differences in cooling and downslope wind speed between the pairs of PW87 simulations are less than $0.4 \mathrm{~K}$ and $0.3 \mathrm{~m} \mathrm{~s}^{-1}$, respectively. For the CCM2 simulations the maximum differences between pairs of simulations are as large as $5.5 \mathrm{~K}$ and $2.1 \mathrm{~m} \mathrm{~s}^{-1}$. This is not a surprising result given the larger change in $z_{H}$ that is applied to the CCM2 cases.

For the SL parameterization $\left[F_{H}\left(\mathrm{Ri}_{B}\right)\right]$ sensitivity cases (CCM2.zh.0/PW87.zh.0 and CCM2.zh.10/PW87.zh.10) the differences in the downslope wind speed and potential temperature are much greater than is found for the $z_{H}$ sensitivity cases (Table 6). The downslope wind speed differs by over $7 \mathrm{~m} \mathrm{~s}^{-1}$, and the potential temperature differs by over $20 \mathrm{~K}$ for the zero ambient flow cases. Smaller, but still large, differences in these quantities are found for the $10 \mathrm{~m} \mathrm{~s}^{-1}$ ambient flow cases as well.

These differences are caused by the different values of $F_{H}$ in the two SL parameterizations for high $\mathrm{Ri}_{B}$ conditions (Fig. 4). For the simulations initialized with no ambient flow, the initial turbulent cooling occurs under very weak wind conditions (a minimum wind speed of $1 \mathrm{~m} \mathrm{~s}^{-1}$ is imposed for all of the SL parameterizations) and thus high $\mathrm{Ri}_{B}$ conditions. From the results presented in Table 4 it is known that the CCM2 SL significantly underestimates the $\mathrm{SH}$ flux when $\mathrm{Ri}_{B}>0.10$, while the PW87 SL significantly overestimates the downward SH flux for the same conditions. The initially larger downward SH flux in the PW87.zh.0 case compared to the CCM2.zh.0 case causes the katabatic flow to become stronger in the PW87.zh.0 simulation. This stronger flow further enhances the turbulent transfer of heat from the atmosphere to the surface (see Table 1) in the PW87.zh.0 case relative to the CCM2.zh.0 case. This then perpetuates the initial differences between the two simulations.

The differences between the simulations using the two different SL parameterizations are reduced when an ambient wind speed of $10 \mathrm{~m} \mathrm{~s}^{-1}$ is imposed. This occurs because the larger wind speed reduces $\mathrm{Ri}_{B}$, and $F_{H}$ differs by a smaller amount between the two SL parameterizations as $\mathrm{Ri}_{B}$ becomes smaller (Fig. 4). If a functional form of $F_{H}\left(\mathrm{Ri}_{B}\right)$ was used that matched $F_{H, \text { obs }}$, it is likely that the simulated katabatic flow would be 

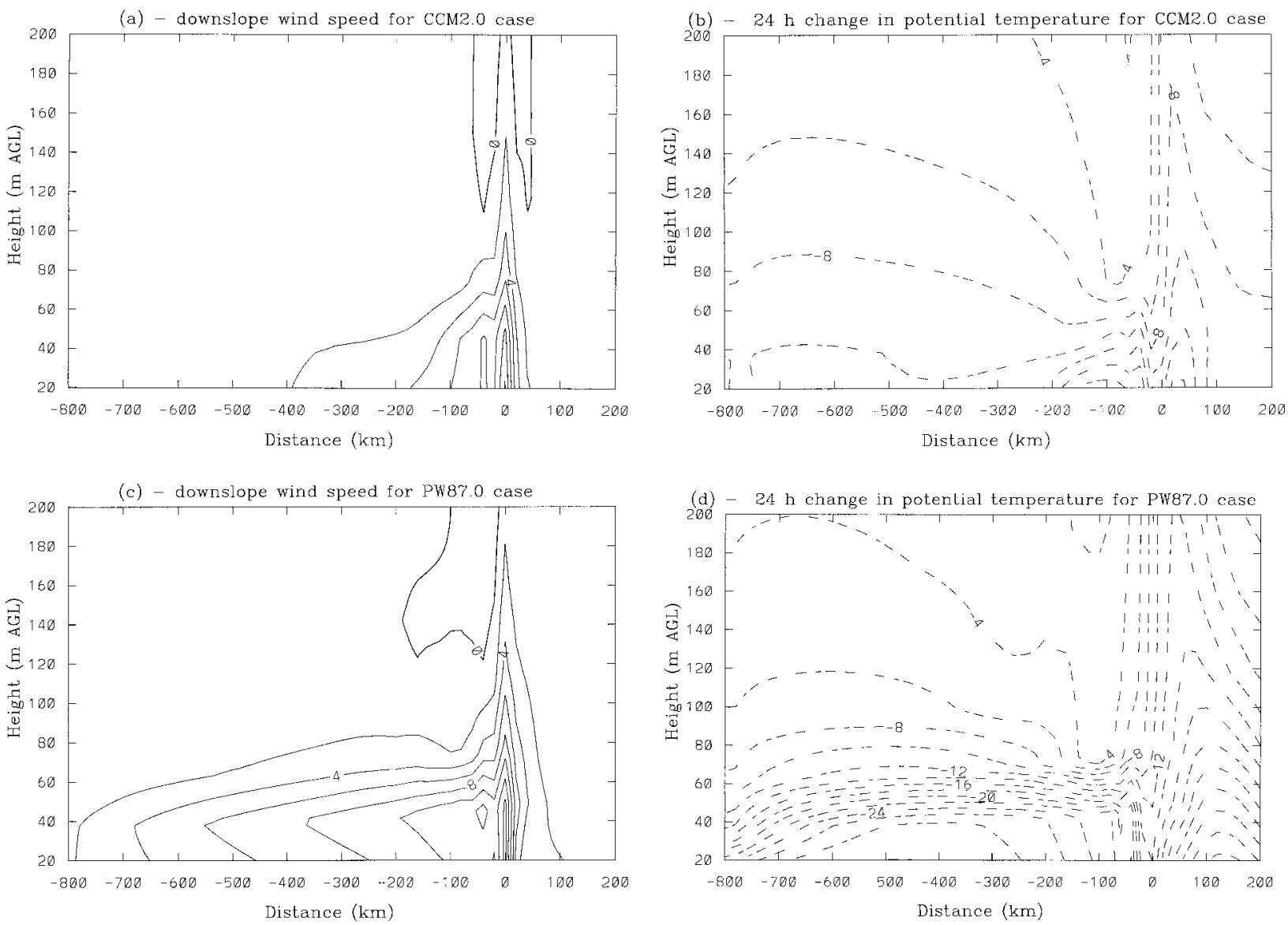

Fig. 6. (a), (c), (e), and (g) Cross sections of the downslope wind speed and (b), (d), (f), and (h) change in potential temperature after $24 \mathrm{~h}$ of model integration for the CCM2.0 case (a) and (b), the PW87.0 case (c) and (d), the CCM2.10 case (e) and (f), and the PW87.10 case (g) and (h). Solid contours represent values $\geq 0$ and dashed contours represent negative values. The contour interval is $2 \mathrm{~m} \mathrm{~s}^{-1}$ for the

intermediate to that found for these sensitivity experiments.

The simulated cooling and katabatic flow is also sensitive to the depth of the SL in the model. Differences in the downslope wind speed and potential temperature are as large as $3.6 \mathrm{~m} \mathrm{~s}^{-1}$ and $11.5 \mathrm{~K}$, and are of similar magnitude for the two different ambient wind speeds considered. The largest differences between the pairs of SL depth sensitivity simulations occurs in the interior of the continent and are caused by a shallower katabatic layer being simulated in the higher-resolution simulations. (Slightly larger magnitude sensitivity to changes in the depth of the SL is also found for simulations using the CCM2 SL parameterization, compared to the PW87 SL.)

The differences in the simulated katabatic flow discussed above are features of local interest and impact the atmospheric structure only over the lowest hundreds of meters of the atmosphere. A farther-reaching effect of the errors in the SH flux calculation can be evaluated in terms of the mass transport in the katabatic layer.

Parish and Bromwich (1997) have shown that the seasonal modulation of the Antarctic katabatic circu- lation is correlated with changes in the atmospheric mass distribution in the Southern Hemisphere. For our sensitivity studies the katabatic layer mass transport is calculated as the product of the downslope wind speed and air density integrated from the surface to the top of the katabatic layer (defined by the $0.1 \mathrm{~m} \mathrm{~s}^{-1}$ downslope wind speed isotach). The ND in the mass transport $\left(\mathrm{ND}_{M}\right)$ between pairs of sensitivity simulations is calculated using an equation that is similar to (2). The average $\mathrm{ND}_{M}$ (calculated over the model terrain slope and adjacent ocean, but excluding the region within 200 $\mathrm{km}$ of the lateral boundaries) and the maximum magnitude $\mathrm{ND}_{M}$ for pairs of sensitivity simulations are listed in Table 7. The along-slope distribution of $\mathrm{ND}_{M}$ for pairs of sensitivity experiments is shown in Fig. 7.

For the pairs of PW87 $z_{H}$ sensitivity cases the mass transport in the katabatic layer is nearly identical and the magnitude of the average $\mathrm{ND}_{M}$ is $\leq 0.01$. In contrast, the average $\mathrm{ND}_{M}$ for the CCM2 simulations ranges from 0.06 to 0.09 , with a maximum $\mathrm{ND}_{M}$ of 0.45 for the zero ambient flow CCM $2 z_{H}$ sensitivity simulations.

Not surprisingly changing the form of $F_{H}\left(\mathrm{Ri}_{B}\right)$ (SL parameterization) used to calculate the $\mathrm{SH}$ flux in the 

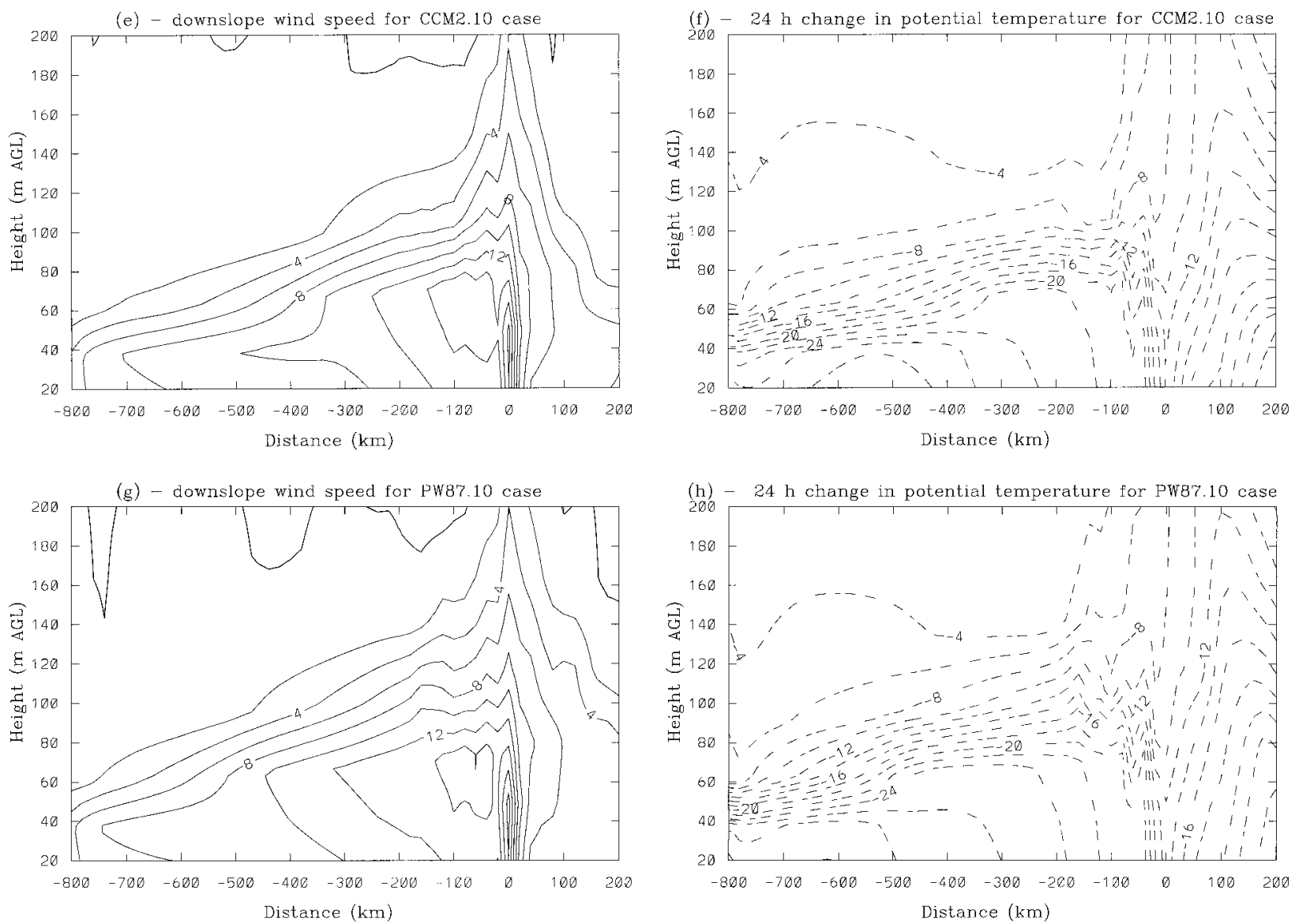

FIG. 6. (Continued) downslope wind speed cross sections and $2 \mathrm{~K}$ for the potential temperature cross sections. Note that the vertical scale is given as height in m AGL rather than height above mean sea level in the figures.

simulations significantly alters the katabatic layer mass transport. For the zero ambient flow cases the maximum $\mathrm{ND}_{M}$ is 2.40 with an average $\mathrm{ND}_{M}$ of 1.28 . This indicates that the simulated mass transport averaged over the model domain in the CCM2.zh.0 simulation is less than half of what is simulated in the PW87.zh.0 simulation. For the cases that were initialized with an ambient wind speed of $10 \mathrm{~m} \mathrm{~s}^{-1}$ the difference in the simulated mass

TABLE 7. Average $\left(\operatorname{avg} \mathrm{ND}_{M}\right)$ and maximum $\left(\max \mathrm{ND}_{M}\right)$ normalized difference of the katabatic layer mass transport for the pairs of simulations listed in the first column of the table. For all cases the katabatic layer mass transport is larger for the second simulation listed in the first column of the table than for the first simulation listed in the first column of the table.

\begin{tabular}{lcc}
\hline \hline \multicolumn{1}{c}{ Cases } & $\operatorname{Avg~ND}_{M}$ & $\operatorname{Max~ND}_{M}$ \\
\hline CCM2.0-CCM2.zh.0 & 0.09 & 0.45 \\
PW87.0-PW87.zh.0 & 0.01 & 0.02 \\
CCM2.10-CCM2.zh.10 & 0.06 & 0.18 \\
PW87.10-PW87.zh.10 & 0.00 & 0.01 \\
CCM2.zh.0-PW87.zh.0 & 1.28 & 2.40 \\
CCM2.zh.10-PW87.zh.10 & 0.09 & 0.22 \\
PW87.0-PW87.dz.0 & 0.27 & 1.81 \\
PW87.10-PW87.dz.10 & 0.15 & 0.27 \\
\hline
\end{tabular}

transport between the CCM2 and PW87 SL parameterization cases is greatly reduced, although the average $\mathrm{ND}_{M}$ for these cases is as large as is found for the most sensitive pair of $z_{H}$ simulations.

Changes in the SL depth also strongly impact the katabatic layer mass transport (Table 7, Fig. 7). For the SL depth sensitivity cases the average $\mathrm{ND}_{M}$ ranges from 0.15 to 0.27 , with an increase in mass transport occurring in the increased vertical resolution simulations. The sensitivity to the SL depth decreases as the ambient flow increases, since the stronger flow generates a deeper katabatic layer that is represented reasonably accurately by either model vertical resolution evaluated.

\section{2) Turbulent COOLING AS AN AGENT OF DIABATIC TEMPERATURE CHANGE}

In the absence of moist processes an atmospheric column can only be cooled through either turbulent or radiative processes. Turbulent heat loss from the atmospheric column occurs at the surface and, therefore, is directly tied to the surface turbulent SH flux. In contrast, direct radiative cooling of the atmosphere occurs over 

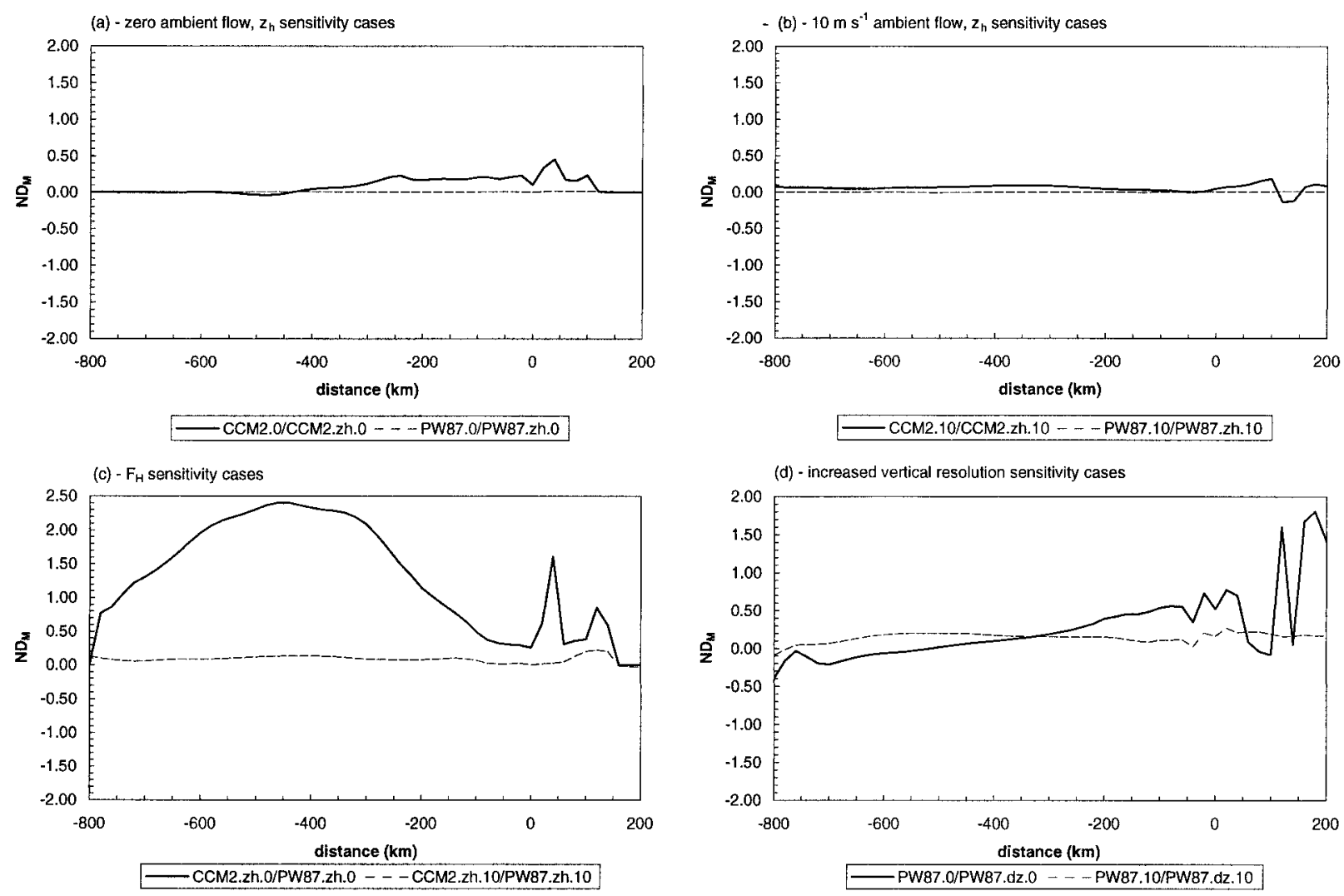

FIG. 7. (a) The value of $\mathrm{ND}_{M}$ as a function of along-slope distance is shown for the zero ambient flow $z_{H}$ sensitivity cases, (b) the $10 \mathrm{~m}$ $\mathrm{s}^{-1}$ ambient flow $z_{H}$ sensitivity cases, (c) the $F_{H}$ sensitivity cases, and (d) the increased vertical resolution sensitivity cases.

the depth of the atmosphere. In this section an evaluation of the contribution of turbulent processes to the total diabatic temperature tendency of the atmospheric column for a dry atmosphere is considered.

Based on the MM5 forecast values of the surface SH flux and the radiative temperature tendency the total diabatic temperature tendency for each model column is calculated. The calculations are performed over a fixed depth of the atmosphere (ranging from 200 to 5000 $\mathrm{m}$. AGL). The turbulent temperature tendency is calculated as the temperature change, for the entire mass of the column considered, that would result from heat loss from the column equal to the forecast turbulent $\mathrm{SH}$ flux. It should be noted that the actual turbulent cooling is confined to a relatively shallow layer of the atmosphere, certainly much less than the 5000-m upper-limit column depth considered here. Our reason for using a deep column is to illustrate that the turbulent temperature tendency, even when "diluted" over a large depth of the atmosphere, is still a large contributor to the total diabatic tendency of the atmospheric column. As the column depth decreases the relative contribution of the turbulent heat loss to the diabatic temperature tendency will increase. The temperature tendency due to radiative effects is calculated as the mass-weighted average of the forecast radiative temperature tendency at each model grid point within the column being considered.

Figure 8 illustrates the fraction of the diabatic temperature tendency due to turbulent cooling processes for the 0 and $10 \mathrm{~m} \mathrm{~s}^{-1}$ ambient geostrophic wind speed simulations, as well as the differences in the fractional cooling rate between the pairs of sensitivity simulations, for an atmospheric column depth of $5000 \mathrm{~m}$. (For comparison the fractional cooling rates are as large as 0.95 for a column depth of $200 \mathrm{~m}$ compared to values as large as 0.6 for a column depth of $5000 \mathrm{~m}$.)

In general the fractional cooling increases as the wind speed increases, due to the enhanced turbulent transfer between the atmosphere and the surface under the strong flow conditions. Peak fractional cooling rates occur near the coast, where the wind speed is greatest and thus the SH flux is largest, with maximum values that are as large as 0.6 (Figs. 8a and 8b).

For the zero geostrophic wind speed cases the fractional cooling in the CCM2 cases decreases dramatically inland from the coast (Fig. 8a). For this SL parameterization the SH flux is quite small under weak wind conditions, and thus the relative contribution of turbulent cooling to the total diabatic cooling is small. The fractional cooling is near 0.3 over the entire length of 

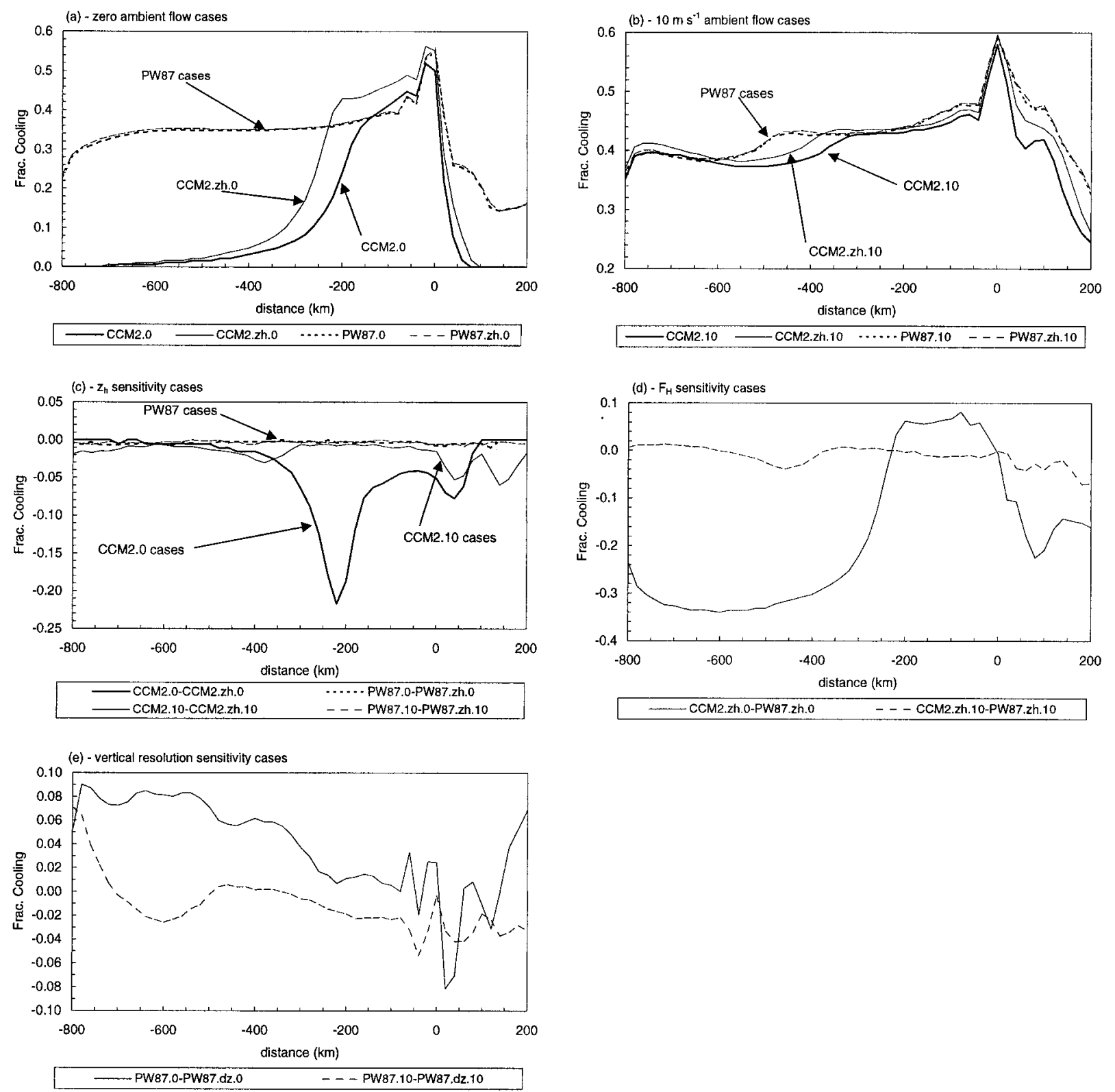

FIG. 8. Values of the fraction of the diabatic cooling due to turbulence (frac. cooling) calculated for a 5000-m-deep atmospheric column are shown for (a) the zero ambient flow cases and (b) the $10 \mathrm{~m} \mathrm{~s}^{-1}$ ambient flow cases. Differences in the fraction of diabatic cooling due to turbulence are shown for (c) the $z_{H}$ sensitivity cases, (d) the $F_{H}$ sensitivity cases, and (e) the vertical resolutions sensitivity cases (e).

the terrain slope for the PW87 zero ambient flow cases, and near 0.4 for the $10 \mathrm{~m} \mathrm{~s}^{-1}$ ambient flow cases, and differs by less than a few percent between the PW87 and PW87.zh simulations (Fig. 8c). For the CCM2 cases, the CCM2.zh.0 case has fractional cooling rates that are up to nearly 0.2 larger than in the CCM2.0 case, and differences as large as 0.05 occur over a length of more than $100 \mathrm{~km}$ of the model domain (Fig. 8c). Differences smaller than 0.05 are found for the $10 \mathrm{~m} \mathrm{~s}^{-1}$ ambient wind speed CCM2 cases, over the entire model domain.
Differences in the fractional cooling between the PW87 and CCM2 simulations are shown in Fig. 8d. The largest differences, which are in excess of 0.3 , occur over much of the model domain, for $x<-300 \mathrm{~km}$, for the zero ambient flow cases. Much smaller differences are found for the $10 \mathrm{~m} \mathrm{~s}^{-1}$ ambient flow cases.

The largest differences in the fractional cooling (larger than 0.05 ) for the SL depth sensitivity cases are found for the zero ambient flow simulations, over the portions of the model domain with the weakest katabatic flow (Fig. 8e). These results are consistent with the fact that 
a shallow turbulent layer is present when the near-surface flow is weak (reduced turbulence generation) and that this shallow turbulent layer will be poorly represented as the vertical resolution is decreased. This misrepresentation of the shallow SL leads to the overestimation of the diabatic cooling contribution by the turbulent SH flux in the coarse vertical resolution simulation.

From Fig. 8 it is noted that changes to the value of $z_{H}$ used to calculate the SH flux in the PW87 SL have a relatively small impact on the simulated diabatic temperature tendency, but that changes to the value of $z_{H}$ used in the CCM2 SL parameterization substantially alter the diabatic temperature tendency (Figs. 8a-c). The greatest differences occur between the CCM2 and PW87 SL parameterizations (Fig. 8d), indicating the sensitivity of the $\mathrm{SH}$ flux calculations to the form of $F_{H}\left(\mathrm{Ri}_{B}\right)$ used in the parameterizations. Changes in the model vertical resolution have an intermediate impact on the simulated diabatic temperature tendency compared to the other sensitivity simulations (Fig. 8e).

\section{Summary and conclusions}

Based on a comparison of calculated and observed surface fluxes at Halley, Antarctica, it is found that many of the widely used SL parameterizations in today's numerical models (including CCM2, CCM3, MM5, and the UKMO Unified Climate Model) tend to underestimate the magnitude of the downward-directed $\mathrm{SH}$ flux under stably stratified conditions. There is also a tendency for these parameterizations to overestimate $u_{*}$, but this effect is found to be of much smaller magnitude. Although data from only one location in the Antarctic are considered it appears that the results may be applicable to conditions over much of Antarctica. The results are least likely to be applicable in the high interior regions of the continent, where additional surface and boundary layer measurements are needed.

The findings in this paper are in contrast to results presented by King and Connolley (1997) and Hines et al. (1999), who found that the turbulent transfer of heat from the atmosphere to the surface in the Antarctic is overestimated in both the UKMO Unified Climate Model and the NCEP MRF model. In these studies the effects of errors in the forecast values of low-level wind speed and temperature inversion strength on the forecast $\mathrm{SH}$ flux values could not be determined unambiguously, and may account for some of the difference between these studies and the current project.

King and Connolley (1997) note that the ratio of the modeled to observed wind speeds, in the UKMO Unified Climate Model at the South Pole, is about 1.5. The calculated $\mathrm{SH}$ flux increases as the low-level wind speed increases, and thus the error in the low-level wind speed in the model contributes to the overestimated downward-directed $\mathrm{SH}$ flux in the model compared to the observations. King and Connolley quantify this effect by assuming that the heat flux changes proportionally to the change in wind speed, but neglect the effect that the increased wind speed has on $\mathrm{Ri}_{B}$ and thus the stability-dependent correction term used in the SL parameterization. Since the relationship between the simulated $\mathrm{SH}$ flux, the wind speed, and $\mathrm{Ri}_{B}$ is nonlinear the use of mean wind speed errors is not strictly applicable in order to evaluate the effects of changes in $\mathrm{Ri}_{B}$ on the calculated $\mathrm{SH}$ flux. Still, a model bias that leads to overestimated low-level wind speeds will reduce $\mathrm{Ri}_{B}$ and will lead to larger downward-directed $\mathrm{SH}$ fluxes being simulated by the SL parameterization than was estimated by King and Connolley. Therefore it is possible that the overestimated downward SH flux forecasts discussed by King and Connolley (1997) and Hines et al. (1999) are the result of errors in the forecast low-level wind speed in the models rather than errors in the SL parameterizations. In fact the overestimated wind speed in the models could mask the errors in the SL parameterizations discussed in this paper (which lead to the calculated downward SH flux being too small).

Another source of errors in the SH fluxes calculated in the UKMO and MRF models discussed by King and Connolley (1997) and Hines et al. (1999) is associated with the height of the lowest model level. The SL parameterizations implicitly assume that the lowest model level is located within the constant flux SL. For the UKMO model the lowest model level is located at a height of $20 \mathrm{~m} \mathrm{AGL}$, while for the MRF model the lowest model level is located at a height of $70 \mathrm{~m}$ AGL. Results in King (1990) indicate that the SL at Halley is often as shallow as $5 \mathrm{~m}$ and, thus, much shallower than the depth of the lowest model layers used in both the UKMO and MRF models. Sensitivity simulations in which the height of the lowest model level is varied indicates that an overly deep lowest model level (and thus SL) will lead to an overestimation of the downward-directed SH flux and provides another explanation for the conflicting results of this study with those of King and Connolley (1997) and Hines et al. (1999).

The error in the calculated $\mathrm{SH}$ fluxes is found to be caused by the assumption that $z_{H}=z_{0}$ in the SL parameterizations. Values of $z_{H}$ determined empirically from the SL measurements at Halley indicate that $z_{H}>$ $z_{0}$. This result is in qualitative agreement with the analysis of King and Anderson (1994) who found that $z_{H}$ is up to three orders of magnitude larger than $z_{0}$ based on observations made at Halley (although estimates of $z_{H}$ from the current dataset are smaller than found by King and Anderson), but disagrees with the theoretical results of Andreas (1987) that suggested $z_{H}<z_{0}$ over snow and ice surfaces. The use of a larger $z_{H}$ compared to $z_{0}$ in the SL parameterizations increases the magnitude of the calculated SH flux while keeping the magnitude of $u_{*}$ unchanged, and removes most of the bias in the calculated $\mathrm{SH}$ fluxes for all but the largest $\mathrm{Ri}_{B}$ cases considered.

The improved results from the SL parameterizations 
when $z_{H}>z_{0}$ is used may reflect a non-physically based improvement. Monin-Obukhov similarity theory, on which the evaluated SL parameterizations are based, does not include a contribution to the calculated fluxes from gravity wave activity, and thus the larger $z_{H}$ may be required to "artificially" increase the magnitude of the calculated fluxes to compensate for the unrepresented gravity wave contribution to the total flux. Additional measurements in the stable SL, which can isolate the gravity wave contributions to the measured fluxes, is needed to resolve this issue.

Evaluation of the impact that underestimating the $\mathrm{SH}$ flux has on numerically simulated katabatic winds is conducted in the context of $2 \mathrm{D}$ numerical experiments. In these experiments changes to $z_{H}$, the form of $F_{H}\left(\mathrm{Ri}_{B}\right)$, or the depth of the SL used to determine the SH flux are found to appreciably alter the simulated katabatic flow. The most significant differences are found when $F_{H}\left(\mathrm{Ri}_{B}\right)$ is varied. For these experiments it is found that the katabatic layer mass transport differs by more than a factor of 2 between the cases considered. Preliminary results from additional numerical experiments indicate that SL parameterizations with $F_{H}\left(\mathrm{Ri}_{B}\right)$ similar to that used in the CCM3, MRF, and PW87 SL parameterizations produce more realistic simulations of katabatic winds over both Antarctica and Greenland.

Future research should address the impact of systematic errors in the SH flux calculations for climate simulations caused by assuming $z_{H}=z_{0}$. Also the discrepancies between the current results and those previously presented in the literature need to be addressed. Using $z_{H}>z_{0}$ in SL parameterizations will likely lead to increased errors in the operational forecasts of the SH flux in the Antarctic due to both the positive bias in the lowlevel wind speed, which has been documented in other studies, as well as errors associated with the coarse vertical resolution used to represent the SL. Finally, the generality of the results presented in this paper need to be evaluated with additional turbulence measurements in the interior of the Antarctic. A measurement program similar to that at Halley, but at the United States research station at the South Pole, would dramatically improve our understanding of SL processes over the Antarctic continent.

Acknowledgments. This research was funded in part by National Science Foundation Grant OPP-9725263 to TRP. The measurements at Halley were funded in part by the European Commission Environment Program, under Contract ENV4-CT95-0076. We thank Dr. P. S. Anderson for running this measurement program. Thanks must also be given to the scientists at the Mesoscale and Microscale Meteorology division at NCAR for their support and assistance with the use of MM5. The comments of three anonymous reviewers helped to clarify and improve this manuscript.

\section{REFERENCES}

Adachi, T., 1974: Characteristics of wind and temperature fluctuations above the sloping surface at Syowa Station, Antarctica. J. Meteor. Soc. Japan, 52, 82-85.

Andreas, E. L, 1987: A theory for the scalar roughness and the scalar transfer coefficient over snow and sea ice. Bound.-Layer Meteor., 38, 159-184.

Blackadar, A. K., 1976: Modeling the nocturnal boundary layer. Preprints, Third Symp. on Atmospheric Turbulence and Air Quality, Raleigh, NC, Amer. Meteor. Soc., 46-49.

Burk, S. D., and W. T. Thompson, 1989: A vertically nested regional numerical weather prediction model with second-order closure physics. Mon. Wea. Rev., 117, 2305-2324.

Businger, J. A., J. C. Wyngaard, Y. Izumi, and E. F. Bradley, 1971: Flux-profile relationships in the atmospheric surface layer. $J$. Atmos. Sci., 28, 181-189.

de la Casinière, A. C., 1974: Heat exchange over a melting snow surface. J. Glaciol., 13, 55-72.

Dudhia, J., 1993: A nonhydrostatic version of the Penn State-NCAR mesoscale model: Validation tests and simulation of an Atlantic cyclone and cold front. Mon. Wea. Rev., 121, 1493-1513.

Grant, A. L. M., and R. D. Watkins, 1989: Errors in turbulence measurements with a sonic anemometer. Bound.-Layer Meteor., 46, 181-194.

Grell, G. A., J. Dudhia, and D. R. Stauffer, 1994: A description of the fifth-generation Penn State/NCAR mesoscale model (MM5). NCAR Tech. Note NCAR/TN-398 + STR, 122 pp.

Hack, J. J., B. A. Boville, B. P. Briegleb, J. T. Kiehl, P. J. Rasch, and D. L. Williamson, 1993: Description of the NCAR Community Climate Model (CCM2). NCAR Tech. Note NCAR/TN-382 + STR, 108 pp.

Halberstam, I., and J. P. Schieldge, 1981: Anomalous behavior of the atmospheric surface layer over a melting snowpack. J. Appl. Meteor., 20, 255-265.

Hines, K. M., R. W. Grumbine, D. H. Bromwich, and R. I. Cullather, 1999: Surface energy balance of the NCEP MRF and NCEPNCAR reanalysis in Antarctic latitudes during FROST. Wea. Forecasting, 14, 851-866.

Hong, S.-Y., and H.-L. Pan, 1996: Nonlocal boundary layer vertical diffusion in a medium-range forecast model. Mon. Wea. Rev., 124, 2322-2339.

Kiehl, J. T., J. J. Hack, G. B. Bonan, B. A. Boville, B. P. Briegleb, D. L. Williamson, and P. J. Rasch, 1996: Description of the NCAR Community Climate Model (CCM3). NCAR Tech. Note NCAR/TN-420 + STR, 152 pp.

King, J. C., 1990: Some measurements of turbulence over an Antarctic ice shelf. Quart. J. Roy. Meteor. Soc., 116, 379-400.

- 1993: Contrasts between the Antarctic stable boundary layer and the mid-latitude nocturnal boundary layer. Waves and Turbulence in Stably Stratified Flows, S. D. Mobbs and J. C. King, Eds., Oxford University Press, 105-120.

— scalar roughness lengths over an Antarctic ice shelf. Bound.Layer Meteor., 69, 101-121.

—, and W. M. Connolley, 1997: Validation of the surface energy balance over the Antarctic ice sheets in the U.K. Meteorological Office unified climate model. J. Climate, 10, 1273-1287.

_, and J. Turner, 1997: Antarctic Meteorology and Climatology. Cambridge University Press, 409 pp.

— S. D. Mobbs, J. M. Rees, P. S. Anderson, and A. D. Culf, 1989: The stable Antarctic boundary layer experiment at Halley Station. Weather, 44, 398-405.

Kobayashi, S., and T. Ishida, 1979: Some characteristics of turbulence in katabatic winds over Mizuho Plateau, East Antarctica. Antarct. Rec., 67, 75-85.

Lettau, H., A. Riordan, and M. Kuhn, 1977: Air temperature and twodimensional wind profiles in the lowest 32 meters as a function of bulk stability. Meteorological Studies at Plateau Station, Ant- 
arctica, J. A. Businger, Ed., Antarctic Research Series, Vol. 25, Amer. Geophys. Union, 77-91.

Louis, J.-F., 1979: A parametric model of vertical eddy fluxes in the atmosphere. Bound.-Layer Meteor., 17, 187-202.

Parish, T. R., and K. T. Waight, 1987: The forcing of Antarctic katabatic winds. Mon. Wea. Rev., 115, 2214-2226.

— in surface pressure over Antarctica. J. Geophys. Res., 102, $13785-13792$.

Phillpot, H. R., and J. W. Zillman, 1970: The surface temperature inversion over the Antarctic continent. J. Geophys. Res., 75, 4161-4169.

Sasaki, H., 1979: Preliminary study on the structure of the atmo- spheric surface layer in Mizuho Plateau, East Antarctica. Antarct. Rec., 67, 86-100.

Schwerdtfeger, W., 1984: Weather and Climate of the Antarctic. Elsevier, $261 \mathrm{pp}$.

Stull, R. B., 1988: An Introduction to Boundary Layer Meteorology. Kluwer Academic, $666 \mathrm{pp}$.

Willmott, C. J., 1982: Some comments on the evaluation of model performance. Bull. Amer. Meteor. Soc., 63, 1309-1313.

Wyngaard, J. C., and S.-F. Zhang, 1985: Transducer-shadow effects on turbulence spectra measured by sonic anemometers. J. Atmos. Oceanic Technol., 2, 548-558.

Zhang, D.-L., and R. A. Anthes, 1982: A high-resolution model of the planetary boundary layer-Sensitivity tests and comparisons with SESAME-79 data. J. Appl. Meteor., 21, 1594-1609. 